\title{
Review
}

\section{Developmental Acquisition of p53 Functions}

\author{
Sushil K. Jaiswal ${ }^{*, 1,3}$, Sonam Raj $j^{*, 2}$ and Melvin L. DePamphilis ${ }^{1,4}$ \\ 1 National Institute of Child Health and Human Development, Bldg. 6A, Rm 3A15, 6 Center Dr, Bethesda MD \\ 20892 \\ 2 National Cancer Institute, Bldg. 37, Rm 1062, 37 Convent Dr, Bethesda MD 20892 \\ 3 Current address: National Human Genome Research Institute, Bldg. 49, Rm 4C36, 49 Convent Dr., Bethesda \\ MD 20892 \\ 4 Correspondence: depamphm@nih.gov \\ *These authors contributed equally to this review.
}

\begin{abstract}
Remarkably, the p53 transcription factor, referred to as "the guardian of the genome", is not essential for mammalian development. Moreover, efforts to identify p53-dependent developmental events have produced contradictory conclusions. Given the importance of pluripotent stem cells as models of mammalian development, and their applications in regenerative medicine and disease, resolving these conflicts is essential. Here we attempt to reconcile disparate data into justifiable conclusions predicated on reports that p53-dependent transcription is first detected in late mouse blastocysts, that p53 activity first becomes potentially lethal during gastrulation, and that apoptosis does not depend on p53. Furthermore, p53 does not regulate expression of genes required for pluripotency in embryonic stem cells (ESCs); it contributes to ESC genomic stability and differentiation. Depending on conditions, p53 accelerates initiation of apoptosis in ESCs in response to DNA damage, but cell cycle arrest as well as the rate and extent of apoptosis in ESCs are p53-independent. In embryonic fibroblasts, p53 induces cell cycle arrest to allow repair of DNA damage, and cell senescence to prevent proliferation of cells with extensive damage.
\end{abstract}

Keywords: pluripotent; embryo; stem cells; genomic stability; cell cycle; apoptosis; differentiation; cancer

\section{Current Consensus on $\mathrm{p} 53^{1}$}

p53 is referred to as "the guardian of the genome", because it maintains genomic stability by arresting proliferation of cells with damaged DNA, thus minimizing the risk of tumor development by maintaining a pool of healthy cells [1]. Nevertheless, p53 is not essential for embryonic development. Mice nullizygous for $p 53$ ( $p 53-/-$ mice) do not die until they succumb to tumors as adults [2-4]. Moreover, the p63 and p73 homologs of p53 also are not essential for development, and they are not functionally redundant with p53 [5]. Therefore, the p53 family of proteins is not essential for mammalian development.

In differentiated cells, p53 operates primarily through transcriptional activation of the cyclin-dependent kinase inhibitor p21 to prevent cells from entering S-phase, and the pro-apoptotic proteins PUMA and NOXA/PMAIP1 [6,7] to activate the rapid induction of apoptosis when the effects of cell stress are too great to be reversed. Remarkably, neither p21 nor PUMA are required for mouse development. p21-/- mice develop spontaneous tumors at an average age of 16 months, whereas wild-type mice are tumor-free beyond 2 years of age [8]. Puma-/- mice recapitulate virtually all of the apoptotic deficiencies in p53/- mice [9].

Over half of all human tumors express a mutated p53 in which the mutation down-regulates p53 activity. Inactivation of the p53 gene leads to three hallmarks of

${ }^{1}$ For clarity and uniformity, the names of proteins are in capitals (e.g. OCT4) and the names of genes in sentence case (e.g. Oct4). Where helpful, the official name is given first followed by a popular name. 
cancer: genomic instability, metastasis, and drug-resistance [10]. Restoration of wild-type p53 protein can result in tumor regression and prolonged mouse survival [11]. Besides mutations in the p53 gene, loss of p53 activity can also result from epigenetic silencing, from disruption of pathways that activate $\mathrm{p} 53$ in response to DNA damage, from viral proteins that impair p53 activity, and from up-regulation of MDM2 expression [12-17].

In response to cellular stress such as inhibition of DNA replication or mitosis, double-strand DNA breaks, changes in the oxidative state, ribonucleotide depletion, or oncogene activation [18], p53 activates transcription of genes involved in many different events. These include maintaining genomic stability by inducing cell cycle arrest, apoptosis or senescence [19-21], regulating homeostasis and metabolism [22], regulating pluripotency and differentiation [23,24], triggering inflammation [25], reducing reproduction [26], regulating aging [27], and stimulating tissue regeneration [28]. Recent evidence indicates that p53 also has a role in enabling cells to adjust their metabolism in response to changes in glucose and other nutrient levels, oxygen availability, and reactive oxygen species $[29,30]$. Consequently, p53 has been reported to induce expression of hundreds of different genes that affect viability [31].

Analysis of 3661 p53 target genes gleaned from multiple sources concluded that only 343 are p53 target genes with high-confidence [32]. This represents an 11-fold reduction in the number of p53 target genes reported in the literature and suggests that p53 targets about $1.6 \%$ of the approximately 21,000 human protein coding genes [33]. These highconfidence p53 target genes function in multiple processes (Figure 1).

The nature of the phenotypic response to $\mathrm{p} 53$ activation is generally proportionate to the amplitude, duration, and nature of the activating signal [18]. Severe stress induces apoptosis and senescence, whereas milder stress leads to a transient growth arrest coupled with an attempt to deal with the cause of stress and repair the damage caused by it.

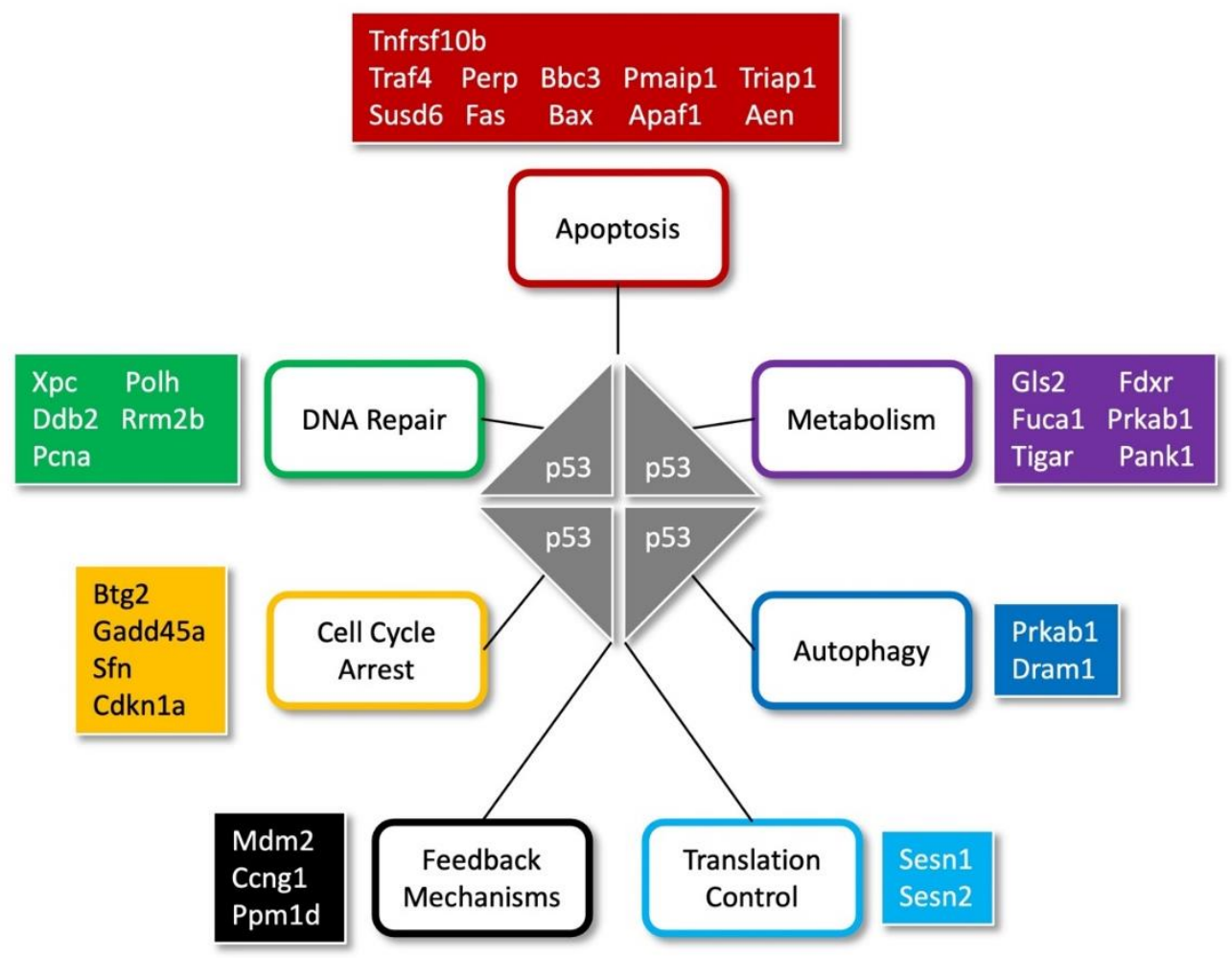

Figure 1. High confidence p53 target genes and the functions they facilitate. p53 binds to DNA as a homotetramer. Examples of proteins encoded by p53 target genes function in multiple processes include, but are not limited to, cell cycle arrest, DNA repair, apoptosis, metabolism, autophagy, translation control and feedback mechanisms. Adapted from [32]. Symbols are from the HUGO gene nomenclature committee (https://www.genenames.org/). 


\section{Current Consensus on Preimplantation Mouse Development}

Mammalian development begins when an egg is fertilized by a sperm to produce a 1-cell embryo termed the zygote [34,35]. The zygote then undergoes a series of cell cleavage events to produce a blastocyst that implants into the uterine endothelium to produce an embryo (Figure 2). The 1-cell to 8-cell embryos consist of totipotent blastomeres encapsulated by a thick transparent membrane termed the zona pellucida. Totipotent cells can develop into a new organism; they can give rise to both the placenta and the embryo. Pluripotent cells can become any type of cell in the body, as exemplified by embryonic stem cells (ESCs). Multipotent stem cells can differentiate into two or more distinct cell types.

During the 8-cell to 32-cell stage of development, the blastomeres develop cell-to-cell adhesion, and the outer blastomeres differentiate into the multipotent trophectoderm while the remaining blastomeres form the pluripotent inner cell mass. The epithelial trophoblast cells (trophectoderm) give rise only to cells required for implantation and placentation, whereas the inner cell mass of the blastocyst (recognized upon formation of a blastocoel cavity) differentiates into the pluripotent epiblast and the multipotent primitive endoderm. Following implantation of the blastocyst into the uterine membrane, the primitive endoderm differentiates into multipotent visceral and parietal endoderm that give rise to internal layers of various organs. The other two multipotent primitive cell layers are derived from the epiblast. Primitive mesoderm gives rise to muscle and blood cells, whereas primitive ectoderm gives rise to skin and neuronal cells.

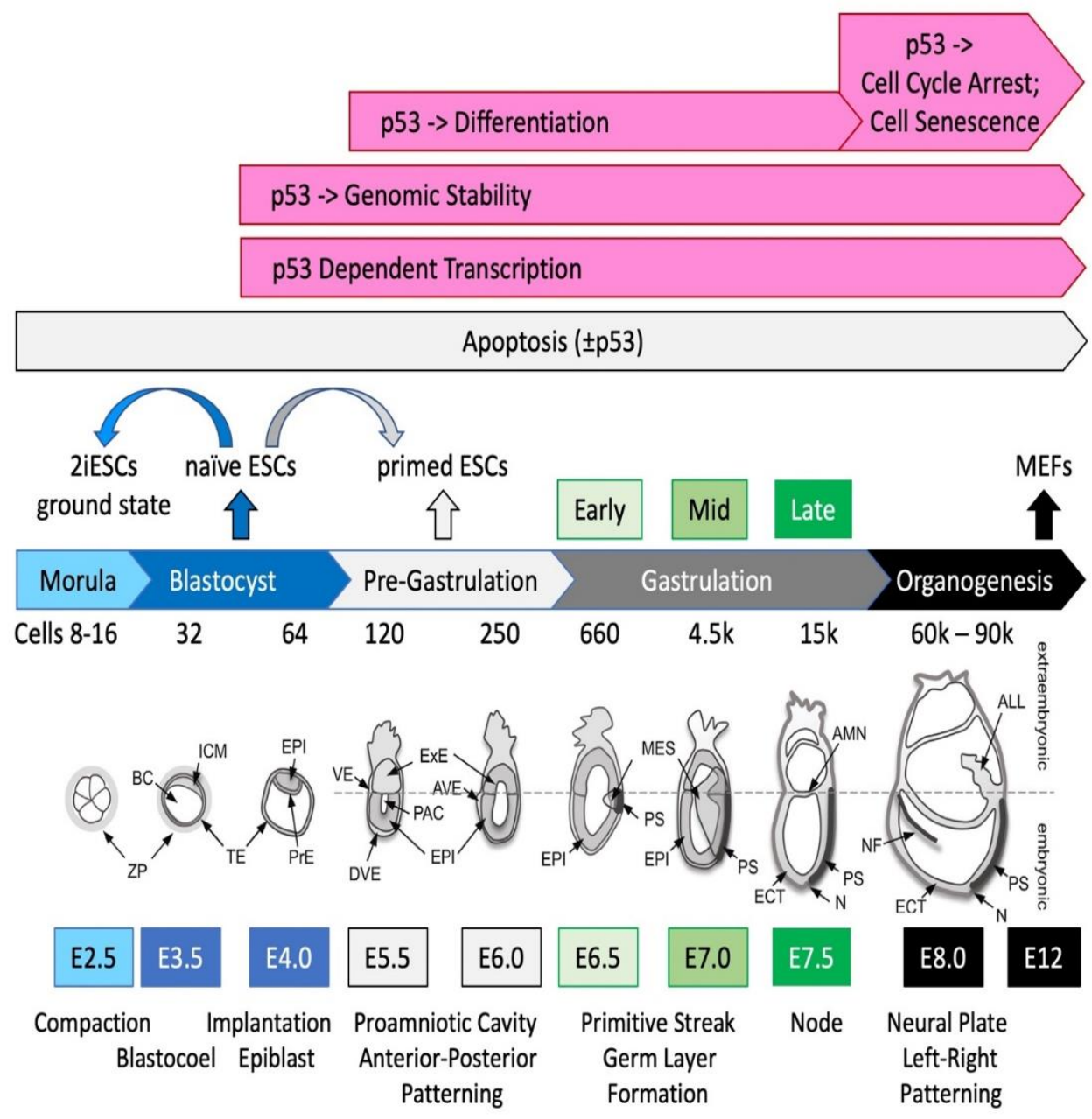

Figure 2. Preimplantation and early post-implantation mouse development. The p53 transcription factor and tumor suppressor protein is not essential for mammalian embryonic development, although it does facilitate several important events beginning with maintaining genomic stability by preventing polyploidy and aneuploidy during self-renewal of pluripotent embryonic stem cells 
(ESCs). Self-renewal refers to the ability of pluripotent stem cells to undergo an indefinite number of cell divisions without losing their ability to differentiate into cells derived from all three primary germ layers. In ESCs, p53 facilitates differentiation during gastrulation, although it is not required for either transient cell cycle arrest or induction of apoptosis in response to DNA damage . In mouse embryonic fibroblasts (MEFs), DNA damage induces either p53-facilitated transient cell cycle arrest or cell senescence. The range or average number of cells for the entire conceptus (embryonic days post-coitum E0.5-E4.5) or the epiblast and the germ layers (E5.5-E8.0), and the key morphogenetic events at each age are indicated. Abbreviations: ALL (allantois), AMN (amnion), AVE (anterior visceral endoderm), BC (blastocyst cavity), DVE (distal visceral endoderm), ECT (ectoderm), EPI (epiblast), ExE (extraembryonic ectoderm), ICM (inner cell mass), MES (mesoderm), N (node), NF (neural fold), PAC (proamniotic cavity), PrE (primitive endoderm), PS (primitive streak), TE (trophectoderm), VE (visceral endoderm), ZP (zona pellucida). Adapted from [36].

\subsection{Transcription of the p53 Gene During Embryonic Development}

p53 transcripts have been detected at low levels throughout mammalian development. In mice, transcripts from genes involved in programmed cell death (Trp53, Pdcd4, $\mathrm{Bad}, \mathrm{Bax}, \mathrm{Bcl} 211$, and $\mathrm{Bcl}$ ) are present from the 1-cell embryo through the blastocyst stage with greatest number of p53 transcripts/embryo in blastocysts [37]. Later studies in humans quantified the number of TP53, BRCA1, BRCA2, ATM, RB1, MAD2, BUB1, APC and ACTB transcripts/embryo/cell from oocytes through blastocysts [38]. The average number of p53 transcripts/embryo was 141 in oocytes, 51 in 2-4 cell embryos, 72 in 5-10 cell embryos, and 1120 in blastocysts; the number of p53 transcripts/cell was 21, 14, 8 and 14, respectively. Thus, the number of p53 transcripts per cell is comparatively constant during preimplantation development.

From zygote to adult, genes involved in cell proliferation and programmed cell death are expressed at varying levels in virtually every cell [39]. All cells express p53 transcripts until 10 days post-coitum, but at later stages in development, only specific differentiating tissues showed high levels of expression. Terminally differentiated tissues exhibited very low levels of p53 mRNA, suggesting a strong correlation between p53 levels and the fraction of embryonic cells undergoing proliferation or differentiation.

\section{2. p53-Dependent Embryonic Phenotypes}

In mouse embryonic stem cells and early embryos, p53 restricts expression of the DNA methyltransferases Dnmt3a and Dnmt3b while up-regulating Tet1 and Tet2, which promote DNA demethylation. Hence, p53 helps maintain DNA methylation homeostasis and clonal homogeneity, a function that may contribute to its tumor suppressor activity [40]. Despite the fact that p53 is not essential for mammalian development, p53-/- embryos can display developmental phenotypes [41]. Depending on their genetic background, some p53-/- embryos exhibit exencephaly [42,43], defects in eyes and teeth [43-45], and reduced pregnancy rates and litter sizes that result from decreased uterine levels of LIF interleukin-6 [46]. These effects reflect the fact that, although the p53 protein is largely inactive in stem cells, when activated, p53 helps to commit these cells to developmental lineages through a series of epigenetic changes [7]

\section{What Next?}

Although much has been learned, questions still remain unresolved due largely to two facts: (1) p53 affects expression of hundreds of different genes required to maintain cell viability. (2) p53 is not essential for mammalian development. Therefore, the question is not whether p53 is required for a specific event to occur during development, but whether or not p53 contributes significantly to that event.

When does p53 activity first appear during mammalian development? Does p53 affect genomic stability in embryonic cells as it does in adult cells? Does p53 help maintain a pluripotent state? Does p53 facilitate apoptosis or cell differentiation? 


\section{4. p53 Activity Begins in Pluripotent Stem Cells and Becomes Critical with Gastrula- tion}

Presumably, p53 maintenance of genomic stability and induction of the WNT signal transduction pathway require p53-dependent transcription of specific genes. Thus, the question arises as to when p53-dependent transcription become significant during embryo development.

\section{1. p53 Activity Is First Detected at the Late Blastocyst Stage}

Transgenic mice in which ectopic expression of a EGFP reporter gene is driven by a p53-dependent response element from either the cyclin-dependent kinase inhibitor Cdkn1a/p21 or the pro-apoptotic p53 upregulated modulator of apoptosis Bbc3/Puma promoter demonstrate that p53 transcriptional activity exists as early as late stage blastocysts and early post-implantation epiblast [47] (Figure 3). Furthermore, double-strand DNA breaks introduced by X-irradiation of embryos at either E3.5 (blastocysts) or E9.5 (organogenesis) revealed that p53+/+ embryos die more frequently than p53-/-embryos, whereas p53-/- embryos exhibit more developmental anomalies [48]. X-irradiated p53+/+ embryos undergoing organogenesis contain a greater number of apoptotic cells than p53-/- embryos. p53 appears to facilitate apoptosis in response to double-strand DNA breaks induced by X-irradiation of mouse embryos, but only after they developed to late stage blastocysts (E5) [49]. No significant change in cell proliferation was observed following X-irradiation, but wild-type blastocysts exhibited 2 to 3-times more apoptotic cells than p53-/- blastocysts. Apoptosis, defined as TUNEL-positive DNA-positive cell fragments, occurred primarily in the inner cell mass. Thus, p53 transcriptional activity and DNA damage is evident as early as the late blastocyst stage and increases during organogenesis. 


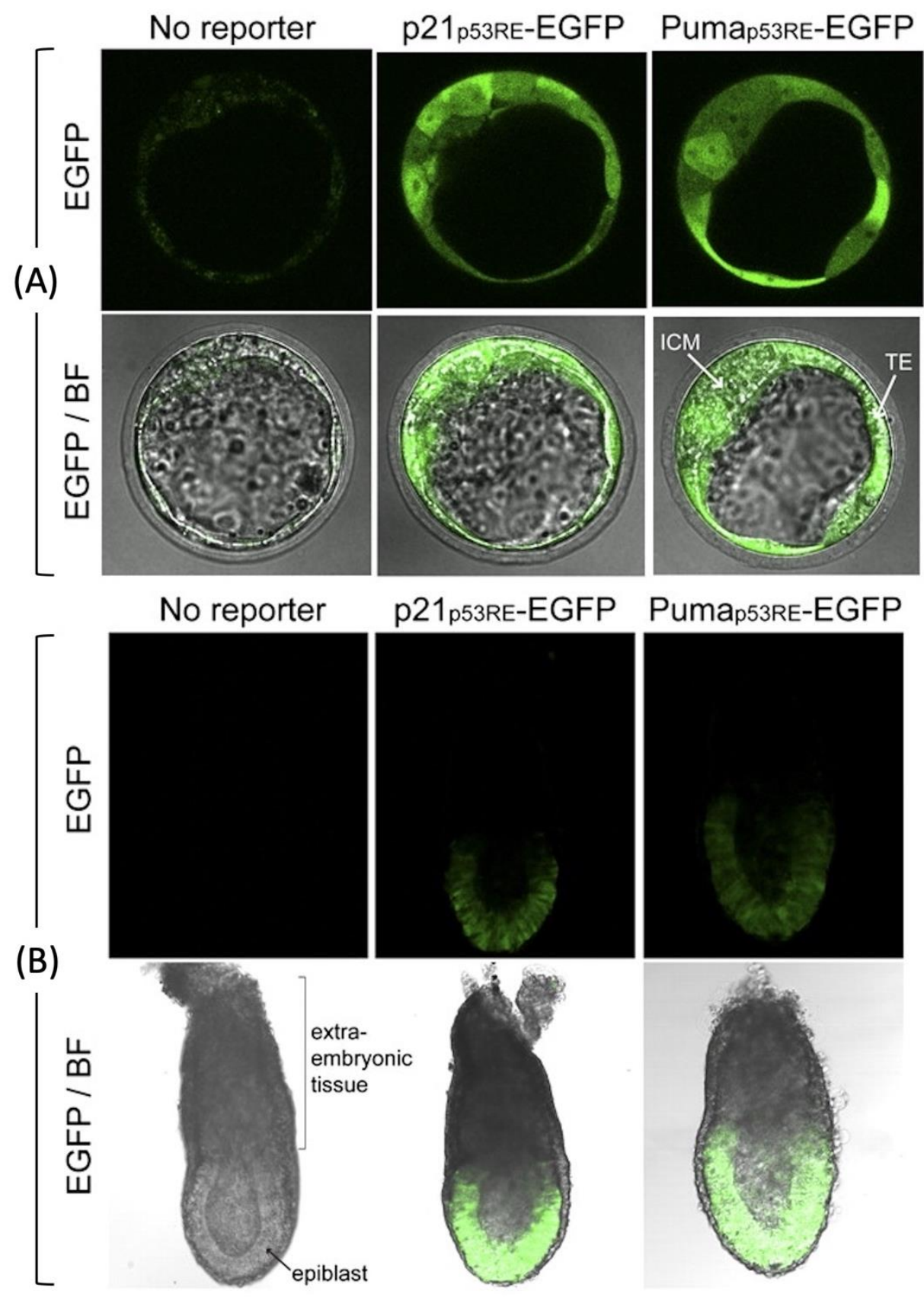

Figure 3. p53 transcriptionally activity at the beginning of mouse development. p53 activity was assayed in early stage embryos isolated from mice homozygous for reporter genes expressing enhanced green fluorescence protein (EGFP) from either the p21 gene's p53 response element or the Puma gene's p53 response element and examined immediately by confocal microscopy [47]. (A) At embryonic day E3.5, EGFP fluorescence was detected in all blastocyst cells, including the inner cell mass (ICM), and trophectoderm (TE). The large blastocoel cavity identifies these examples as latestage blastocysts. (B) EGFP fluorescence was also detected in E6.5 post-implantation reporter embryos but only in the epiblasts and not in the extraembryonic tissues. BF indicates bright field microscopy.

Nevertheless, p53-dependent transcription of endogenous genes in ESCs is suppressed by multiple mechanisms. The bulk of p53 protein is localized to the cytoplasm in naïve ESCs, and p53 activity is maintained at low levels by MDM2 [50-52]. SIRT1 prevents translocation of cytoplasmic p53 to the nucleus [53], and AURKA inactivates p53 by phosphorylating it [54]. 
This apparent contradiction between ectopic EGFP expression and endogenous gene expression reflects the fact that the number of transcripts produced from the EGFP reporter gene, and the number of transcripts produced from the endogenous p21 and Puma genes were not determined. Thus, the simplest explanation is that endogenous p53-dependent transcription at the beginning of mouse development is low in pluripotent embryonic cells compared with differentiated embryonic cells, in which case the primary role of p53 is to facilitate the transition from a pluripotent state to a differentiated state. In support of this hypothesis, ESC differentiation responds to changes in the cellular level of p53. In wild-type ESCs, the MDM2 specific inhibitor nutlin induces ESC differentiation as a consequence of p53 activation, p21 up-regulation and cell cycle arrest $[55,56]$.

\section{2. p53 Activity Is Regulated Post-Translationally and Cannot Induce Lethality Until Gastrulation}

Under normal conditions, p53 expression is very low; it is a short-lived protein whose stability and activity are regulated by post-translational modifications such as phosphorylation, methylation and acetylation that are critical for p53 activation, and by association with specific p53 regulatory proteins such as MDM2 and MDM4/MDMX [57-59]. MDM2 is a p53 target gene that encodes a ubiquitin ligase that mediates degradation of p53, thereby creating a feed-back loop that regulates p53 activity. MDM4 Inhibits p53 by binding to its transcriptional activation domain. MDM4 can reverse MDM2-targeted degradation of p53 while maintaining suppression of p53 transactivation and apoptotic functions. In addition, the 'retinoblastoma-binding protein' RBBP6/PACT [60-62] and the 'protein activator of interferon induced protein kinase EIF2AK2' PRKRA/RAX/PACT [63,64] have been reported to regulate p53 activity.

Gastrulation occurs from E6.25 to E9.5 wherein the epiblast gives rise to the embryo proper through differentiation into the three primary germ layers, ectoderm, mesoderm and endoderm [65]. p53 activity is suppressed in mice until post-implantation development by virtue of the interaction between p53 and MDM2, MDM4 and PACT/RBBP6 $[57,61]$. Inactivation of the MDM2, MDM4 or PACT/RBBP6 gene in mouse embryos results in lethality, but only in the presence of p53 protein. For Mdm2-/- embryos, demise occurred after implantation of the embryo in the wall of the uterus but before day 7.5 of gestation (taken as E5.5) [66,67]. Furthermore, the presence or absence of normal physiologic levels of Mdm2 in embryonic fibroblasts isolated from 12 to 14 day old embryos has no effect on the growth or tumorigenic potential of p53-deficient mouse embryonic fibroblasts, indicating that $\mathrm{Mdm} 2$ does not have a p53-independent role in regulating cell proliferation [68,69]. For PACT/RBBP6-/- embryos, lethality after implantation but before E7.5 [61]. For MDM4, lethality occurs between E7.5 and E12 [70-72]. All three phenotypes were rescued by transferring the mutated p53 negative regulator gene to a p53-nullizygous mouse background, in which case mice develop normally. Thus, embryonic death in the absence of MDM2, MDM4 or PACT/RBBP6 results from activation of p53 protein.

\subsection{Take-Home Lesson}

p53 activity is first detectable during the late blastocyst stage and confined primarily to pluripotent cells. However, p53 expression is too low to induce either cell cycle arrest or cell death upon release from post-translational regulation by MDM2 or PACT/RBBP6 until after the blastocyst has implanted (E4.5) and gastrulation has begun (E6.25-E7.5, Figure 2). However, DNA damage begins to accumulate in Mdm2-/- blastocysts, but less so in embryos that are null for both Mdm2 and the p53-dependent pro-apoptotic gene Bax, suggesting that unregulated p53 can initiate apoptosis in blastocysts that is not lethal until gastrulation [73]. Nevertheless, in the absence of both MDM2 and BAX proteins, embryonic lethality still occurs during E6.5-E7.5, due to arrest of cell proliferation (presumably senescence). In contrast, Mdm4-/- embryo lethality results simply from p53-dependent arrest of cell proliferation (presumably senescence) [70-72]. 


\section{5. p53 Maintains Genomic Stability During Embryonic Development}

The earliest demonstration of p53-dependent maintenance of genomic stability occurs during embryonic stem cell proliferation when p53 prevents accumulation of polyploid and aneuploid cells [74]. Aneuploidy is a hallmark of cancer [10]. In the absence of p53, polyploid and aneuploid cells arise during the 21 days required for gestation in mice. However, only a fraction of these cells will produce a cancer, thereby accounting for the fact that p53-/- mice do not die until they succumb to tumors as adults.

\subsection{Tetraploidy -> Polyploidy -> Aneuploidy}

Tetraploidy is a precursor to polyploidy and polyploidy leads to aneuploidy [75]. Tetraploidy is an aberrant event that results from endoreplication (multiple S-phases without an intervening mitosis), cytokinesis failure, or mitotic slippage. When that occurs, wild-type mouse embryonic fibroblasts or human fibroblasts are arrested in G1 phase with 4N DNA content, whereas p53-/- cells re-enter the cell cycle and initiate another round of DNA replication [76,77]. p53-dependent cell cycle arrest requires the cyclin-dependent kinase inhibitor p21. The same effects are also observed with human fibroblasts, except that tumor suppressor 'retinoblastoma transcriptional corepressor 1' (RB1) also plays a role. Thus, the p53 dependent checkpoint following disruption of the mitotic spindle functionally overlaps with the p53-dependent checkpoint following DNA damage. In addition, p53 loss dysregulates the spindle assembly checkpoint by up-regulating MAD2, which increases chromosome missegregation and tetraploidization [78]. In the context of tetraploid cells, p53 loss leads to an increased rate of multipolar mitoses and subsequent chromosome missegregation [79]. Consequently, loss of p53 drastically accelerates tumor development in aneuploid cells [80].

\subsection{Teratoma Formation}

Teratomas are solid tumors composed of differentiated cells derived from all three primary germ layers [81]. Both $\mathrm{p} 53+/+$ and $\mathrm{p} 53-/-$ mouse ESCs produce teratomas at ectopic sites [82,83]. During self-renewal, p53-/- ESCs develop a high incidence of karyotype abnormalities [82], and although they retain their ability to contribute to normal development in chimeric embryos, p53-/- ESCs exhibit defects during differentiation [84]. Thus, p53 is not required for ESC differentiation, because both p53+/+ and p53-/- mouse or human ESCs can differentiate in vitro [82,85]. However, p53 does act as a 'guardian of the genome' by inhibiting ESCs with abnormal karyotypes from proliferating. Fibroblasts isolated from p53-/- mouse embryos and then cultured in vitro readily accumulate aneuploid cells [86]. The absence of p53 is not sufficient to cause aneuploidy in vivo, although cells without p53 are prone to accumulate abnormal chromosomes after oncogene activation [87].

\subsection{Take-Home Lesson}

In the absence of detectable p53 transcriptional activity prior to the appearance of embryonic stem cells, p53 begins its role as 'guardian of the genome' during the late blastocyst stage and continues to the adult.

\section{Maintaining the Pluripotent State}

The role of p53 in maintaining a pluripotent state was first suggested by the fact that p53 gene expression is greater in cells derived from 10-14 days old mouse embryos than in cells derived from 16 days old mouse embryos [88]. Subsequent studies confirmed that expression of p53 was high in naïve ESCs [50], downregulated during embryogenesis $[88,89]$, and virtually absent in terminally differentiated cells [90]. More recently, pifithrinalpha (PFT- $\alpha$ ), an inhibitor of p53-dependent transcription, inhibited cell number, colony size, cell cycle progression and DNA synthesis in ESCs, suggesting that in the absence of stress, p53 is required for ESC self-renewal [91]. However, PFT- $\alpha$ inhibition of 
transcription is highly dependent on the p53 target gene selected, and PFT- $\alpha$ is not an effective antagonist of p53 activation by nutlin inhibition of Mdm2 [92].

The pluripotent state is currently attributed to expression of 10 essential transcription factors in human and mouse ESCs [93-97]. They are the 'core genes' Pou5f1p5/Oct4, Sox2, and Nanog, along with Tcf3/E2a, Klf4, Myc/c-Myc, Esrrb, Sall4, Tbx3, and Stat3. Remarkably, only Nanog and Myc are among the 343 genes considered to be regulated directly by the p53 transcription factor [32], and both are down-regulated by p53 [23,24,98]. Therefore, if p53 facilitates maintenance of the pluripotent state, it does so indirectly.

\subsection{Pluripotent Stem Cells Maintain p53 at Low Levels}

In both ESCs and induced pluripotent stem cells (iPSCs), p53 activity is maintained at low levels through post-translational modifications by ubiquitylation, acetylation, phosphorylation, methylation or sumoylation of specific residues in p53 protein [99]. For example, ubiquitylation by MDM2 and TRIM24 maintain low levels of p53 in human ESCs [100]. Phosphorylation of p53 by AURKA at S212 and S312 inhibits differentiation of ESCs [54]. Deacetylation of p53 at K373 by the NAD-dependent deacetylase SIRT1 inhibits nuclear p53 activity [101].

\subsection{Pluripotency Is Maintained Through 553 regulation of LncRNA Expression}

Long non-coding RNAs (LncRNAs), >200 nucleotides with poly-adenylated tail but without an open reading frame, are highly expressed in human pluripotent ESCs [102,103]. Repression of LncRNAs promotes ESC differentiation [102]. More than 40 LncRNAs are expressed in human ESCs, and they are regulated by p53 to maintain a balance between pluripotency and differentiation.

For example, the LncRNAs termed lncPRESS1 and lncPRESS2 maintain pluripotency whereas the LncRNA termed HOTAIRM1 promotes differentiation [104]. lncPRESS1 prevents chromatin localization of SIRT6, which results in histone acetylation at H3K56 and $\mathrm{H} 3 \mathrm{~K} 9$ at the promoters of core pluripotency genes, thereby maintaining their transcription [104]. In human ESCs, H3K56 acetylation is associated the transcriptional activation of core pluripotency genes [105]. lncPRESS4, also known as TUNA (Tcl1 upstream neuronassociated or linc86023), is required for maintenance of pluripotency by directly binding to the promoters of the Nanog, Sox2 and Fgf4 genes [106].

\subsection{Pluripotency Is Maintained Through WNT signaling}

Under stress conditions, p53 stimulates ESCs to secrete WNT ligands that inhibit differentiation, thereby maintaining a pluripotent state [107]. As p53 activates the expression of LIF interleukin-6 [108], the WNT signaling pathway and its synergistic interaction with LIF interleukin-6 play important role in maintaining pluripotency and self-renewal of human and murine cells $[109,110]$.

\subsection{Micro-RNAs Maintain Pluripotency by Inactivating p53}

MicroRNAs (miRs) repress the expression of mRNA targets by promoting translational repression and mRNA degradation. [111]. Their regulatory effects appear complex. miR-294 and miR-302 promote the abbreviated G1 phase of the ESC cell division cycle and suppress ESC differentiation [[112] and references therein]. Other miRNAs can prevent ESC self-renewal, and their activities are antagonized by miR-294 and miR-302. The differentiation-inducing effect of miRNAs was retinoblastoma protein $(\mathrm{Rb})$ dependent, but their ability to inhibit ESC self-renewal was Rb-independent.

In contrast to wild-type ESCs, elevated levels of p53 activity restricts differentiation of ESCs that are deficient in miRs [113]. p53 prevented these ESCs from differentiating in the neural direction. However, expression of miR-302 promoted ESC differentiation by direct interaction with p53. Similarly, inactivation of p53 by association with SV40 large T antigen, by suppressing p53 RNA translation with shRNA, or by genetic ablation of the p53 gene enabled differentiation. In contrast, activating p53 by treating miR-deficient 
ESCs with the MDM2 inhibitor nutlin inhibited neural differentiation. Thus, low levels of p53 allowed differentiation, whereas high levels of p53 inhibited differentiation. Moreover, cellular levels of p53 appear to be regulated by various miRs, presumably in response to environmental signals.

\subsection{Pluripotency Is Maintained Through p53 isoforms}

A transactivation-deficient isoform of p53, $\triangle 40 \mathrm{p} 53$ is highly expressed in ESCs, and is the major p53 isoform during early mouse embryonic development. p53 is maintained in an inactive state by the presence of $\triangle 40 \mathrm{p} 53$. Haploinsufficiency for $\triangle 40 \mathrm{p} 53$ causes a loss of pluripotency in ESCs and compromises their ability to grow, while its increased dosage prolongs pluripotency and inhibits differentiation. $\triangle 40$ p53 controls p53 at targets such as Nanog and the IGF-1 receptor to switch from pluripotent to differentiated cells [114]. $\triangle 40$ p53 overexpression reduces p53 activity by inhibiting its transactivation domain $[115,116]$ and promoting nuclear export of p53- $\triangle 40 \mathrm{p} 53$ heterotetramers [117]. In ESCs, overexpression of $\triangle 40 \mathrm{p} 53$ interferes with the ability of p53 to regulate the transcription of p21, Nanog, and Igf-1R which are involved in the switch between pluripotency and differentiation [23,118,119]. Moreover, N-terminal truncated isoforms $\Delta \mathrm{Np} 73$ of p73 decreases p53 leading to an increase in Nanog gene expression which subsequently enhanced human iPSC generation [120]. Although less explored in stem cell regulation, p63 and p73 functions in cooperation with p53 in the regulation of adult stem-like cells [121].

\subsection{Take-Home Lesson}

p53 does not regulate expression of genes essential for ESC self-renewal. In fact, p53 activity must be maintained at a low level in ESCs to prevent differentiation (section 7). Moreover, p53 activity is not a significant factor in maintaining the pluripotent state. Both wild-type and p53-/- ESCs undergo self-renewal in vitro as well as in vivo. They both proliferate, produce teratomas, contribute to chimeras, and produce living mice. In fact, p53-/ESCs proliferate faster [84] and p53-/- 2-cell embryos development faster [49] than their wild-type counterparts. The primary distinction between wild-type and p53-/- mice is that p53-/- mice accumulate genomic abnormalities during development that eventually result in tumors and lethality.

\section{Pluripotent Stem Cell Differentiation}

\section{1. p53 Facilitates ESC Differentiation}

p53 is not essential for ESC differentiation, because embryos lacking p53 genes can still gastrulate and develop, and newborns can thrive until succumbing to tumors at 3 to 5 months of age [14]. Nevertheless, p53 facilitates differentiation of pluripotent stem cells $[40,84,104]$, and p53 inhibits conversion of differentiated cells into pluripotent cells [122125].

The frequency at which reprogramming of differentiated cells into pluripotent cells by ectopic expression of genes, such as Oct4, Sox2, Nanog and others is suppressed by the high levels of p53 in differentiated cells and stimulated by reducing p53 expression, because p53 represses transcription of the reprogramming genes [23,24]. However, differentiation of ESCs is not induced simply by p53 inhibiting expression of the core pluripotency genes Oct4, Sox2, or Nanog, because these genes are down regulated during LIF-deprivation at equivalent rates in both p53+/+ and p53-/- ESCs [126]. Therefore, if p53 facilitates differentiation of ESCs, it must do so indirectly as well as directly.

\subsection{DNA Damage Induces p53-Dependent Differentiation}

Doxorubicin/Adriamycin increases the number of differentiated colonies appearing in naïve p53+/+ ESCs, but not in p53-/- ESCs, due to p53-mediated transcriptional repression of ESC-specific transcription factors [24]. Doxorubicin also dramatically stimulated expression of genes characteristic of differentiated cells in p53+/+ embryoid bodies, but 
not in p53-/- embryoid bodies. ESC aggregation is the initial step in triggering ESC differentiation in the form of 'embryoid bodies' that consist of cells characteristic of cells derived from the three primary germ layers $[127,128]$. Thus, the ability of DNA damage to promote ESC differentiation is p53-dependent.

\section{3. p53 Can Inhibit Pluripotency}

In response to DNA damage, p53 protein is activated by phosphorylation at S315 and over expressed. Activated p53 binds to the Nanog promoter where it displaces OCT4 and SOX2, thereby suppressing NANOG expression and driving ESCs differentiation $[23,129,130]$. p53 also mediates direct repression of Nanog transcription by recruitment of MSIN3A to p53 bound at the Nanog promoter [23]. MSIN3A is a histone deacetylase that represses transcription [131]. Activation of p53 by treating cells with nutlin, a specific inhibitor of MDM2, also induces ESC differentiation [55]. Nutlin induced suppression of NANOG and OCT4 expression with concomitant induction of GATA4 and GATA6 expression, two transcription factors that are essential for embryonic development during gastrulation [132].

\section{4. p53 As A Barrier To Reprogramming}

Reprogramming differentiated cells into 'induced pluripotent stem cells' is achieved specifically by over expressing the core pluripotency transcription factors OCT4, SOX2 and NANOG, in combination with other transcription factors, such as KLF4, LIN28A/LIN28 and MYC [133]. p53 acts as barrier to reprogramming by inhibiting expression of these genes in differentiated cells. This is evident from the fact that reprogramming p53-/- somatic cells is much easier than reprogramming p53+/+ somatic cells [122125]. Apart from this, MYC activates ARF-dependent and p53-dependent pathways that elevate the p53 barrier to reprogramming [134]. Activation of p53-dependent pathways in response to DNA damage also elevate expression of p53, which suppresses expression of NANOG [135].

\section{5. p53-Dependent Formation of Haploid Cells}

Haploid cells are a characteristic of early post-implantation embryos [136]. Deprivation of LIF interleukin-6 forces naive ESCs to either differentiate in the mesendodermal direction or undergo apoptosis $[137,138]$. Remarkably, LIF-deprivation of naïve ESCs drives formation of haploid-like cells in p53+/+ cells, but not in p53-/- cells [126]. Haploid ESCs are a useful tool for loss-of-function genetic screening [139].

\subsection{Take Home Lesson}

p53 promotes ESC differentiation, and once a differentiated state is produced, p53 activity stabilizes the differentiated state.

\section{DNA Damage Response in ESCs}

\subsection{Physiological States of Pluripotent Embryonic Stem Cells}

ESCs exhibit three physiological states termed 'ground state', 'naïve ', and 'primed' [140-142]. ESCs cultured in the presence of serum and LIF interleukin-6 are considered 'naïve' pluripotent ESCs, because they give rise primarily to somatic tissues and germ cells but not to the trophectoderm. Most studies on ESCs fall into this category (Figure 2).

'Naïve ESCs' cultured in defined medium (no serum) containing two kinase inhibitors, one against MAP2K1/MEK1 and one against FRAT2/GSK-3, are thought to model 'ground-state' pluripotent ESCs, because they can give rise to both extraembryonic (placental and yolk sac) and embryonic (epiblast and its derivatives) cells. 'Ground-state ESCs' are termed 2iESCs [143]. 2iESCs are pluripotent and perform well in chimera formation [144].

'Naïve ESCs' can also differentiate into 'primed ESCs' when cultured in the presence of activin and fibroblast growth factor. Both 'naïve ESCs' and 'primed ESCs' can 
differentiate into mesoderm, endoderm, ectoderm, as well as germ cells. However, 'naïve ESCs' can readily generate chimeric animals, whereas 'primed ESCs' cannot. Therefore, primed ESCs are thought to model the epiblast in early embryos and are termed EpiSCs. In fact, transcriptomes in mouse EpiSCs derived from the pre-gastrula stage to late-budstage embryos are hierarchically distinct from those of ESCs and epiblast ectoderm but similar to the ectoderm of the late-gastrula embryo [145]. Thus, naïve ESCs are thought to model the pre- or peri-implantation embryonic epiblast, whereas EpiSCs model the early post-implantation epiblast [146,147].

\subsection{Cell Cycle Arrest in Naïve ESCs Is Not p53-Dependent}

The absence of a G1-checkpoint together with the presence of a G2-checkpoint is a hallmark of both naïve ESCs and cancer cells [148]. The G2 checkpoint appears as a transient accumulation of cells containing 4N DNA in response to DNA damage prior to induction of apoptosis[149]. Double-strand DNA breaks induced by culturing cells with the topoisomerase II inhibitor doxorubicin/Adriamycin activates the G2 checkpoint in naïve ESCs regardless of the presence or absence of p53 [24,126,150,151], p21 or PUMA [[126], figure $4 \mathrm{C})$ ].

The G1 checkpoint is a more nuanced response to cell stress that retards entrance into $S$ phase [152]. Naïve mouse ESCs lack a G1 DNA damage checkpoint [126,150,151,153155], although it might exist in 2iESCs [156]. Naive ESCs are characterized by hyper-phosphorylated RB1 protein, lack of G1 control, and rapid progression through the cell cycle. In contrast, 2iESCs have a longer G1-phase with hypophosphorylated RB1, implying that they have a functional G1 checkpoint. The RB1-dependent G1 restriction point is active in ESCs propagated under $2 \mathrm{i}$ culture conditions but abrogated by ERK-dependent phosphorylation when cultured in serum [157]. 
(A) Vehicle
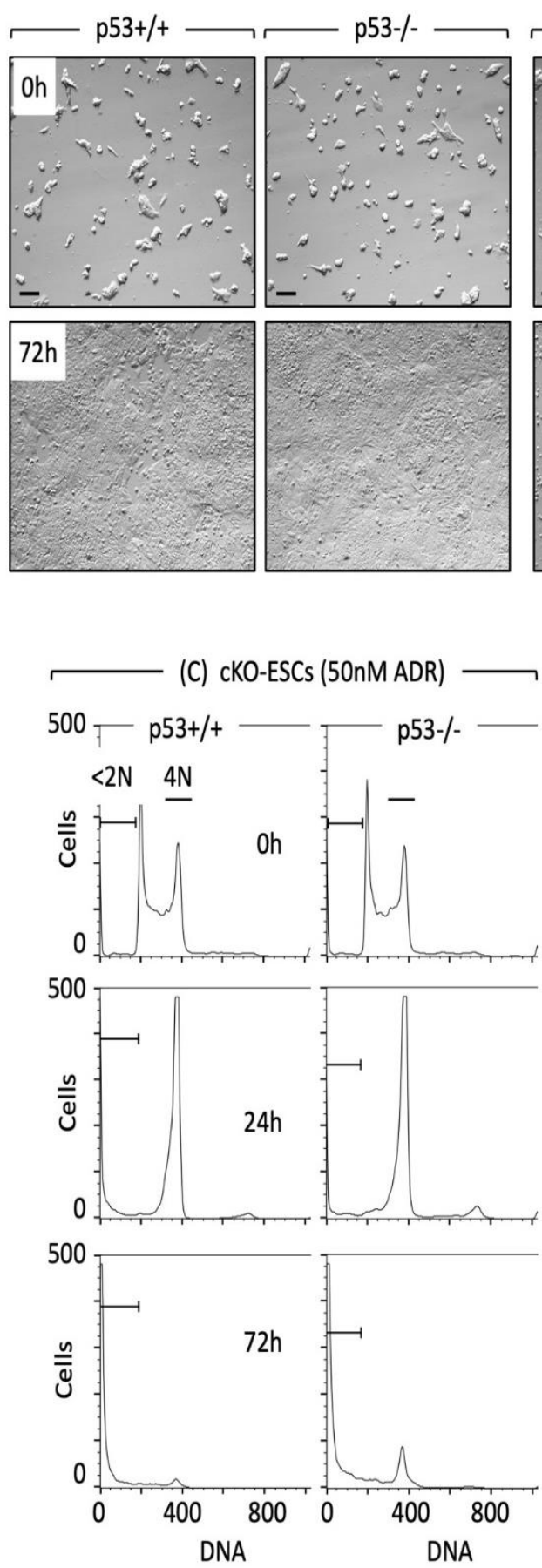

(B) 50nM ADR
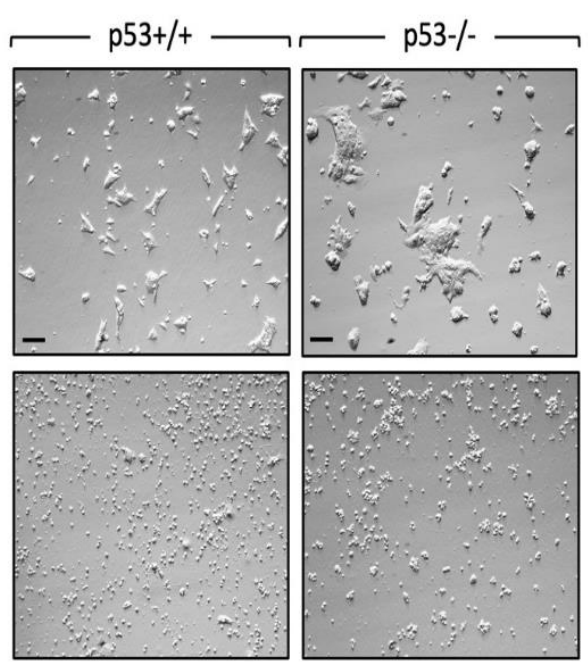

p53+ p53-
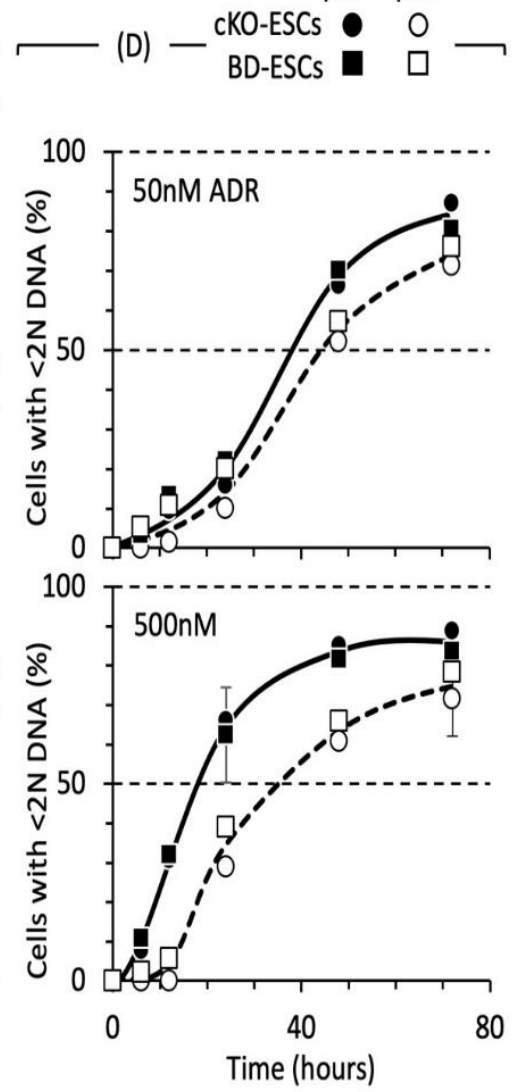

Figure 4. Cell cycle arrest and apoptosis in naïve ESCs are not dependent on p53. Low concentrations of Adriamycin/doxorubicin (ADR) were equally toxic to both p53+/+ and p53-/- mouse naïve ESCs. Blastocyst derived (BD) ESCs were seeded at 14,000 cells $/ \mathrm{cm}^{2}$ and then cultured with either vehicle (A) or 50nM ADR (B). Death was confirmed by combining attached and unattached cells and then staining with trypan blue. Results with conditional knockout (cKO) ESCs were indistinguishable from those with BD-ESCs. Taken from figures S1 and 1 [126]. (C) 50nM ADR triggered the G2-checkpoint within 24 hours and apoptosis within 72 hours in both p53+/+ and p53-/- cKOESCs. Similar results were obtained with BD-ESCs. Attached and unattached cells were combined, their DNA stained with propidium iodide, and then fractionated according to DNA content using fluorescence activated cell sorting. Cells with $<2 \mathrm{~N}$ DNA content (apoptotic cells) and cells with $4 \mathrm{~N}$ DNA content (G2/M phase cells) are indicated. (D) Cells with $<2 \mathrm{~N}$ DNA content were quantified as a function of time cultured with ADR. These data were normalized to $0 \%$ at zero hours. Error bars 
indicate \pm SEM. Solid symbols are p53+/+ cells. Open symbols are p53-/- cells. cKO-ESCs are circles. BD-ESCs are squares. Panels C and D are examples from figures 2 and S2 in [126].

\subsection{Apoptosis in Naïve ESCS Is Not p53-Dependent}

Given that p53 activation in mice does not induce cell death until gastrulation, and that p53 is not required to activate the G2 checkpoint, one would expect that pluripotent stem cells would not require 553 to induce apoptosis in response to DNA damage or other cell stresses. Remarkably, of the nine studies that have addressed this issue, three concluded that p53 is not required for DNA damage to induce cell death $[126,151,153]$ and six concluded that p53 is required [150,155,158-160]. Six studies compared p53+/+ with p53-/ESCs $[126,151,153,155,158,159]$. Two studies used shRNA to constitutively suppress p53 expression [150,160]. One study relied solely on changes in p53 expression in response to apoptotic stimuli [52].

Since pluripotent stem cells are programmed to either proliferate, differentiate, or die, Jaiswal and coworkers [126] investigated multiple parameters that might affect naïve ESCs. They found that, regardless of their derivation, naïve ESCs do not require p53, p21 or PUMA either to activate the G2-checkpoint or to undergo programmed cell death rapidly and efficiently via a non-canonical apoptosis pathway. The effects of the concentration of the DNA damaging agent commonly used in these studies (doxorubicin/Adriamycin) and cell confluency were marginal, but the effects of cell differentiation were dramatic; p53-dependent regulation of cell division and apoptosis were acquired during p53dependent differentiation of ESCs in vitro.

To eliminate the possibility that these conclusions depended on either the source or derivation of ESCs, wild-type and p53-/- ESCs derived directly from blastocysts were characterized in parallel with ESCs in which the p53 genes were ablated in vitro. The effects of doxorubicin in these two ESC derivations were indistinguishable over a 40-fold range of concentrations, and cell culture conditions were compared over a 50-fold range of seeding densities. To eliminate methodology-dependent biases, apoptosis was quantified by time dependent increases in annexin- $\mathrm{V}$ binding to detect apoptosis, in propidium iodide staining to distinguish apoptosis from necrosis, and in trypan blue staining to distinguish live cells from dead cells, as well as time dependent loss of DNA to establish cell death. Analyses of p53, p21, PUMA, $\gamma$-H2AX, PARP, and CASP3 proteins were done to confirm genotypes, DNA damage, cell cycle arrest and apoptosis. Canonical apoptosis involves cleavage of CASP3, whereas non-canonical apoptosis does not. Non-canonical apoptosis was confirmed by translocation of AIFM from the cytoplasm to the nucleus.

The inhibitory effect of only 50nM doxorubicin on naïve ESCs - regardless of the presence or absence of p53 - is evident from visual inspection of cultured cells (Figure $4 \mathrm{~A}, \mathrm{~B})$. The lethal effect of doxorubicin is evident from the accumulation of cells with $<2 \mathrm{~N}$ DNA content (Figure 4C,D). Short exposure (24 hours) of low concentration (50nM) of doxorubicin to mouse ESCs, then allowing them to recover for 96 hours proved that even minimal DNA damage is enough to induce apoptosis in mouse ESCs regardless presence of $\mathrm{p} 53$.

\subsection{DNA Damage Response in Ground-State 2iESCs}

Studies on the role of p53 in ground-state $2 \mathrm{iESC}$ s produced contradictory results that mirror those reported for naïve ESCs. Two studies in mouse 2iESCs revealed that DNA damage induced either by aphidicolin inhibition of DNA polymerase-alpha or doxorubicin inhibition of topoisomerase II activates genes characteristic of zygotic gene expression in mouse 2-cell to 4-cell embryos [161,162]. Both studies concluded that the mechanism driving this expression is mediated by an ATR and CHK1 response to double-strand DNA breaks. However, one study concluded that activation required p53 expression [162], whereas the other study concluded that it did not [161]. Critical experiments in which p53+/+ and p53-/- 2iESCs were compared were carried in both studies, but with opposite 
results. A third study concluded that doxorubicin induced p53-dependent apoptosis in 2iESCs [156].

\subsection{Reconciling Disparate Data}

\subsubsection{Bases for Reconciliation}

Contradictory results concerning the DNA damage response during early mammalian development can be reconciled on the following bases: (1) Suboptimal culture conditions for ESCs can result in spontaneous differentiation or cell death. (2) Treatment of cells with compounds at far greater concentrations that required to affect a specific target invariably affects unintended targets that can produce unexpected side effects. (3) Analysis of nullizygous cell lines is imperative for determining whether or not a gene is required for a particular function. (4) Time dependent comparisons of p53-/- with p53+/+ cell lines are imperative to determine whether or not a gene is required to complete a particular function. (5) Constitutive suppression of genes with shRNA selects for clones that remain viable, thus selecting for off-target mutations in addition to the targeted gene.

\subsubsection{Reconciliation of Naïve ESC Data}

Six of the studies described above compared ESCs derived from p53-/- blastocysts produced by mating p53+/- mice with p53+/+ ESCs from the same matings $[61,126,151,153,155,159]$. Remarkably, two studies using blastocyst derived-ESCs (BD-ESCs) from the same source (Rudolf Jaenisch, MIT, Cambridge, MA) reported contradictory results. One found that $1.84 \mu \mathrm{M}$ Doxorubicin (ADR) rapidly induced apoptosis in $>90 \%$ of p53+/+ and p53-/- cells [153], whereas the other reported that the same concentration of ADR induced apoptosis in $50 \%$ of p53+/+ cells but $0 \%$ of p53-/- cells [159].

The simplest explanation is that culturing ESCs to "sub-confluence" before adding ADR [159] created conditions in which excessively high concentrations of drug induced apoptosis in p53+/+ cells more rapidly than in p53-/- cells, as shown in other studies $[126,153]$. For example, ESCs undergoing self-renewal should not be allowed to proliferate to $>80 \%$ confluency, because clumps of p53+/+ ESCs tend to differentiate [163], and p53-dependent events are clearly associated with differentiated cells.

Depending on seeding density and ADR concentration, ADR triggers p53-dependent apoptosis an average of $8.4 \pm 0.5$ hours earlier than p53-independent apoptosis, but both p53+/+ and p53-/- naïve ESCs complete apoptosis within 72 hours (Figure 4D). As little as $0.05 \mu \mathrm{M}$ Doxorubicin is sufficient to induce apoptosis at the same time in both p53+/+ and p53-/- naïve ESCs which then proceeds to completion at equivalent rates. The fact that ectopic over-expression of certain p53 mutations also suppressed ADR-induced apoptosis [159] simply reflects the fact that p53 affects expression of hundreds of different genes, some of which affect apoptosis. Many naturally occurring p53 mutations have the opposite effect; they gain additional oncogenic functions that endow cells with growth and survival advantages [164]. In addition, culture conditions are critical to maintain the pluripotent ESC state [141] and to prevent DNA damage from rapidly accumulating in ESCs cultured under suboptimal conditions [165]. Suboptimal culture conditions might well contribute to conflicting results.

Remarkably, a second contradiction emerged from two studies using same source of ESCs (Yang Xu, Univ. California, San Diego). Both studies concluded that p53 is not required for cell cycle arrest [126,155] and their results with p53+/+ ESCs are indistinguishable, regardless of cell seeding density or ADR concentration [126,155]. However, one study concluded that p53 is essential for ADR-induced apoptosis [155] whereas the other study concluded that efficient apoptosis induced either by ADR or other stress inducers is not p53-dependent [126]. Reconciliation is achieved by virtue of the fact that results with blastocyst derived ESCs (BD-ESCs) were virtually indistinguishable from results with p53-/- ESCs derived by ablating the p53 genes in ESCs homozygous for a conditional p53 gene knockout [126]. Moreover, Li and co-workers relied on CASP3 cleavage to confirm apoptosis, which they detected with a monoclonal antibody specific for the cleaved form. 
Thus, they did not recognize that the extent of CASP3 cleavage was insignificant. Moreover, the time delay for initiation of apoptosis exhibited by naïve ESCs cultured with high concentrations of ADR meant that cleaved CASP3 did not appear until after 24 hours. CASP3-dependent apoptosis also rapidly declines in p53-/- ESCs cultured under stress, such as the extremely high seeding density $\left(260,000\right.$ cells $\left./ \mathrm{cm}^{2}\right)$ used in [155]. This was not a problem using the seeding densities in [126].

Remarkably, two reports from the same laboratory reported apparently conflicting results. One report on induced UV-dependent DNA-damage in p53-deficient ESCs indicated that apoptosis is p53-independent [151], whereas another report from the same laboratory concluded that apoptosis is p53-dependent [158]. This conundrum likely resulted from the fact that the p53-deficient cells in these studies exhibited a complex karyotype that might include additional genetic defects. Neither report provided evidence that the cells used were pluripotent stem cells.

Another study did not compare p53+/+ cells with p53-/- cells [52]. Instead, their conclusion that p53 is required for apoptosis in naïve ESCs was based solely on changes in p53 expression in response to apoptotic stimuli. Such changes in p53 expression are equally consistent with a role for p53 in cell differentiation. ESCs under stress characteristically undergo either differentiation or apoptosis [55,104], and changes observed in gene expression and relocalization of p53 from cytoplasm to nucleus are characteristics of ESC differentiation as well as apoptosis.

Two studies concluded that ADR or etoposide-induced apoptosis was p53-dependent in ESC clones where either human TP53 [160] or mouse Trp53 [150] was suppressed constitutively by shRNA. Reconciliation comes from three possibilities. First, neither study excluded the possibility that off-target effects also repressed expression of genes required for apoptosis. Second, selection of viable ESC lines in these studies would select clones resistance to apoptosis, because constitutive suppression of p53-expression by shRNA in mouse ESCs and embryos promotes clonal heterogeneity by disrupting DNA methylation homeostasis [40]. Third, since ESCs under stress characteristically undergo either differentiation or apoptosis [55,104], changes observed in gene expression and relocalization of p53 from cytoplasm to nucleus are characteristics ESC differentiation as well as apoptosis.

\subsubsection{Reconciliation of Ground-State 2iESC Data}

Three studies have reported the effects of doxorubicin on mouse p53+/+ and p53-/2iESCs. One study cultured 2iESCs with $1 \mu \mathrm{M}$ doxorubicin for 6 hours and concluded that the DNA damage response was p53-dependent [162]. Another study carried out the same experiment using $1 \mu \mathrm{g} / \mathrm{mL}(1.84 \mu \mathrm{M})$ doxorubicin for 48 hours and concluded that the DNA damage response was p53-independent [161]. Still a third study cultured 2iESCs with $1 \mu \mathrm{M}$ doxorubicin for 16 hours and observed that p53+/+ cells underwent apoptosis more quickly than p53-/- cells (63\% p53+/+ cells versus 13\% p53-/- cells) [156]. These results could easily be reconciled if the experiments did not use excessively high concentrations of doxorubicin and if they monitored the effects of doxorubicin over time.

Similar conditions with naïve ESCs revealed that apoptosis begins more quickly in p53+/+ cells than in p53-/- cells, particularly with excessively high concentrations of doxorubicin, but the rates at which cells undergo apoptosis are equivalent, and the extent of apoptosis within 48 to 72 hours is equivalent [126,153]. As little as $0.05 \mu \mathrm{M}$ doxorubicin is sufficient to induce apoptosis in naïve ESCs (Figure 4). Depending on seeding density and doxorubicin concentration, p53+/+ ESCs initiate apoptosis 8.4 \pm 0.5 hours earlier than p53/- ESCs, but both p53+/+ and p53-/- ESCs complete apoptosis within 72 hours (Figure 4D). To determine whether or not p53 is essential for a DNA damage response in ground-state $2 \mathrm{iESC}$ requires that the response of $2 \mathrm{iESCs}$ to different extents of DNA damage is characterized over time.

A separate concern is that 2iESC culture conditions enforce self-renewal and a dramatic loss of spontaneously differentiating cells (Navarro, 2018). So far, only naïve ESCs 
can proliferate and transit easily to the 'ground-state' under these conditions, whereas neither EpiSCs nor differentiated somatic cells survive these conditions. In addition, the application of CRISPR-Cas9 technology to isolate ESC clones with specific gene alterations raises the possibility that additional 'off-target' mutations might be included that affect gene expression, cell proliferation, or cell death.

\subsection{Take-Home Lesson}

Cell cycle arrest in naïve ESCs is p53-independent. Similarly, both the rate and the extent of apoptosis in naïve ESCs is p53-independent. However - depending on experimental conditions - p53 can accelerate initiation of apoptosis by a few hours. Recognizing this distinction requires both time dependent assays and DNA damaging agent concentration dependent assays. Results with naïve ESCs appear to be true for 2iESCs as well, and is likely to be true for primed EpiSCs, although this hypothesis has not yet been tested. However, these conclusions are consistent with the fact that inactivation of any one of the three proteins essential for post-translational regulation of p53 activity (section 1.3), does not arrest embryonic development until gastrulation or later (section 4.2). Therefore, the level of p53 activity in vivo is not sufficient to induce cell cycle arrest or apoptosis until gastrulation.

\section{DNA Damage Response in Differentiated Cells}

\subsection{A p53-Dependent DNA Damage Response Is Acquired During ESC Differentiation}

Depriving naïve ESCs of LIF interleukin-6 forces them to either differentiate in the mesendodermal direction or undergo apoptosis [137,138]. Under these conditions, LIF-deprivation of p53+/+ ESCs increased genomic stability, suppressed the DNA damage induced G2-checkpoint, and increased the rate and extent of DNA damage-induced apoptosis [126]. The G2-checkpoint in ESCs was p53-independent, but after ESC differentiation in vitro, the G2-checkpoint was evident only in p53-/- cells; differentiation of p53+/+ ESCs resulted in loss of the G2-checkpoint. Moreover, apoptosis in either p53+/+ or p53-/- ESCs included cleavage of caspase-3, whereas apoptosis in differentiated ESCs did not. Thus, LIF-deprivation of naïve ESCs in vitro transformed pluripotent cells into differentiated cells with characteristics similar to oncogenic MEFs.

\subsection{Viability of Embryonic Fibroblasts Is p53-Independent}

Early passage p53-/- mouse embryonic fibroblasts (MEFs) isolated from E12 to E14 divide faster than wild-type MEFs, achieve higher cell densities, and have a higher fraction of division-competent cells at low cell density. The fraction of p53-/- MEFs with 2N DNA content (G1 phase) is less than in wild-type MEFS, consistent with a p53-dependent G1 checkpoint. p53+/+ MEFs senesce in response to excessive DNA damage, whereas p53-/- MEFs develop aneuploidy and chromosomal abnormalities Thus, loss of p53 in MEFs confers a proliferation advantage, but not immortality [86].

In contrast with embryos undergoing gastrulation, deletion of $\mathrm{Mdm} 2$ has no effect on viability of MEFs [68,69]. Moreover, p53-/- MEFs and p53-/-;Mdm2-/- MEFs were indistinguishable in their proliferation, response to genotoxic agents, genetic instability, and ability to form spontaneous tumors. Thus, in the absence of p53, deletion of Mdm2 has no additional effects on cell proliferation, cell cycle control, or tumorigenesis in differentiated embryonic cells.

\subsection{DNA Damage Induces p53-dependent Senescence in Embryonic Fibroblasts}

p53 induces cellular senescence when cell cycle arrest is not enough to repair DNA damage. In cells with oncogenic activation, telomere shortening, or oxidative stress, cellular senescence prevents proliferation permanently, while retaining the cell's function $[30,166]$. However, release from non-senescence temporary cell cycle arrest can lead to proliferation of cells with oncogenic potential and development of tumors [21]. 
Only p53+/+ MEFs upregulate expression of p53, p21, and PUMA in response to double-strand DNA breaks introduced by doxorubicin [126]. Nevertheless, MEFs respond to low levels of either natural or induced DNA damage by undergoing p53-dependent senescence rather than apoptosis [68,86,126,167], whereas p53-/- MEFs undergo apoptosis $[126,168,169]$. Cell senescence is preceded by p53-dependent complete cell cycle arrest wherein cells do not accumulate in a specific cell cycle phase, but simply stop proliferating in place [170]. In the absence of p53, MEFs respond to DNA damage with a transient G2 checkpoint followed by caspase-3 independent apoptosis [126,168,169].

At high doxorubicin concentrations, MEFs exhibit p53-independent apoptosis [126,171]. Similarly, in the absence of MDM2, artificially high levels of p53 induce apoptosis [172]. Thus, the choice between senescence and apoptosis appears to depend on the cellular level of activated p53 protein.

\subsection{Apoptosis Is p53-Dependent In Embryonic Fibroblasts Immortalized With an Oncogene}

MEFs exhibit p53-dependent apoptosis or premature senescence when they are immortalized with an oncogene such as adenovirus E1a [173-176], Myc [177] or oncogenic Ras [169]. In contrast, normal p53+/+ MEFs undergo complete cell cycle arrest in response to double-strand DNA breaks [126,178-180], whereas p53-/- MEFs continue to proliferate until they undergo apoptosis $[126,171]$.

\subsection{Take-Home Lesson}

Only when embryonic development has produced differentiated fibroblasts, has p53 activity been demonstrated to significantly increase the rate and extent at which DNA damage induces cell cycle arrest to allow repair of DNA damage, and cell senescence to prevent proliferation of cells with DNA damage. Whether or not DNA damage can also induce apoptosis in embryonic cells remains to be determined.

\section{Summary}

Analysis of the of effects of p53 on mammalian development reveals several surprising conclusions. Although p53 mRNA has been detected from zygote to adult (sections $1.2,2.1)$, p53 protein has not. In fact, evidence for p53-dependent transcription first appears during mouse development in the inner cell mass of late blastocysts, and the p53-specific regulatory protein MDM2 first becomes essential for mouse development when gastrulation begins by preventing p53 activity from arresting embryonic development (sections 4.1-2). Thus, p53 activity appears to begin with formation of pluripotent stem cells and thereafter accumulates as cells undergo differentiation, suggesting that totipotent blastomeres undergo cell cleavage in the absence of p53 activity.

p53-mediated cell cycle arrest allows non-malignant as well as malignant cells to repair damaged DNA. When DNA repair is complete, cells can reenter the normal cell cycle. In contrast, when cells have serious DNA damage, p53 exerts its pro-apoptotic function to eliminate these cells, thereby preventing transfer of damaged DNA to daughter cells [181-183]. This function of p53 is first detected with embryonic fibroblasts where p53 significantly increases the rate and extent at which DNA damage induces cell cycle arrest to allow repair of DNA damage, and cell senescence to prevent proliferation of cells with DNA damage while maintaining their metabolic contribution. Ablation of Mdm2, Mdm4 or Rbbp6 at the beginning of mouse development results in post-implantation lethality, but whether the failure of embryos to continue development results from high levels of p53 activity inducing cell cycle arrest, apoptosis or cell senescence is not clear. What is clear, is that p53 activity must be regulated during gastrulation and subsequent embryonic development. Nevertheless, several conclusions as to the role of p53 at the beginning of mammalian development are justified.

The ability of ESCs to undergo self-renewal is unaffected by the presence or absence of p53, revealing that p53 does not play a significant role in maintaining expression of genes required for pluripotency (section 6). However, the ability of ESCs to maintain 
genomic stability during self-renewal is p53-dependent (section 5), thus p53's role as 'guardian of genome' begins with formation of pluripotent stem cells. In addition, p53 facilitates differentiation of pluripotent stem cells and inhibits reprogramming of differentiated cells into pluripotent cells (section 7). Therefore, although p53 is not essential for cell differentiation during gastrulation, it does facilitate this event.

The DNA damage response in embryonic cells appears more complex, but justifiable conclusions are possible by analysis of critical differences in experimental conditions (section 8.5.1). In the case of naïve ESCs, a G1 phase cell cycle arrest is absent and a transient G2 phase cell cycle arrest is p53-independent. Moreover, DNA damage induced apoptosis occurs at the same rate and to the same extent in p53-/- ESCs as in p53+/+ ESCs. However, depending on experimental conditions, initiation of apoptosis is accelerated by several hours in p53+/+ ESCs (8.5.2). When differences in experimental conditions are taken into account, the same conclusions could apply to 2iESCs, as well (sections 8.4, 8.5.3). Results with EpiSCs have yet to be reported.

Given that fact that p53 is neither essential for ESC renewal nor differentiation, which is evident from the facts that embryos lacking p53 genes continue to gastrulate and develop, and that newborns thrive until succumbing to tumors, then how is the genome protected prior to gastrulation? The answer is that p53 is neither required for cell cycle arrest nor apoptosis in either naïve or ground-state ESCs. Therefore, regardless of the cellular stress and regardless of the genomic defect, totipotent and pluripotent stem cells can undergo apoptosis prior to implantation. Thus, p53-independent apoptosis provides a mechanism for promoting implantation of healthy embryos.

The biological significance of what is learned through characterization of ESCs in vitro depends entirely on their ability to model events demonstrated in vivo. The lessons learned from studies on the DNA damage response in both 2iESCs and naïve ESCs demonstrate the challenges involved.

\section{Supplementary Materials:}

Author Contributions: All the authors wrote and revised the manuscript. All the authors have read and agreed to the published version of the manuscript.

Funding: The work was funded by the NICHD Intramural Research Program, Grant/Award Numbers: ZIA HD000506, ZIA HD000507.

Institutional Review Board Statement:

Informed Consent Statement:

Data Availability Statement:

Acknowledgments:

Conflicts of Interest: The authors declare no conflict of interest

\section{Literature Cited}

1. Lane, D.P. Cancer. p53, guardian of the genome. Nature 1992, 358, 15-16, doi:10.1038/358015a0.

2. Donehower, L.A.; Harvey, M.; Slagle, B.L.; McArthur, M.J.; Montgomery, C.A., Jr.; Butel, J.S.; Bradley, A. Mice deficient for p53 are developmentally normal but susceptible to spontaneous tumours. Nature 1992, 356, 215-221, doi:10.1038/356215a0.

3. Jacks, T.; Remington, L.; Williams, B.O.; Schmitt, E.M.; Halachmi, S.; Bronson, R.T.; Weinberg, R.A. Tumor spectrum analysis in p53-mutant mice. Curr Biol 1994, 4, 1-7, doi:10.1016/s0960-9822(00)00002-6. 
4. Purdie, C.A.; Harrison, D.J.; Peter, A.; Dobbie, L.; White, S.; Howie, S.E.; Salter, D.M.; Bird, C.C.; Wyllie, A.H.; Hooper, M.L.; et al. Tumour incidence, spectrum and ploidy in mice with a large deletion in the p53 gene. Oncogene 1994, 9, 603609.

5. Van Nostrand, J.L.; Bowen, M.E.; Vogel, H.; Barna, M.; Attardi, L.D. The p53 family members have distinct roles during mammalian embryonic development. Cell Death Differ 2017, 24, 575-579, doi:10.1038/cdd.2016.128.

6. Aubrey, B.J.; Kelly, G.L.; Janic, A.; Herold, M.J.; Strasser, A. How does p53 induce apoptosis and how does this relate to p53-mediated tumour suppression? Cell Death Differ 2018, 25, 104-113, doi:10.1038/cdd.2017.169.

7. Levine, A.J.; Berger, S.L. The interplay between epigenetic changes and the p53 protein in stem cells. Genes Dev 2017, 31, 1195-1201, doi:10.1101/gad.298984.117.

8. Martin-Caballero, J.; Flores, J.M.; Garcia-Palencia, P.; Serrano, M. Tumor susceptibility of p21(Waf1/Cip1)-deficient mice. Cancer Res 2001, 61, 6234-6238.

9. Yu, J.; Zhang, L. No PUMA, no death: implications for p53-dependent apoptosis. Cancer Cell 2003, 4, 248-249, doi:10.1016/s1535-6108(03)00249-6.

10. Hanahan, D.; Weinberg, R.A. Hallmarks of cancer: the next generation. Cell 2011, 144, 646-674, doi:10.1016/j.cell.2011.02.013.

11. Ventura, A.; Kirsch, D.G.; McLaughlin, M.E.; Tuveson, D.A.; Grimm, J.; Lintault, L.; Newman, J.; Reczek, E.E.; Weissleder, R.; Jacks, T. Restoration of p53 function leads to tumour regression in vivo. Nature 2007, 445, 661-665, doi:10.1038/nature05541.

12. Eischen, C.M.; Weber, J.D.; Roussel, M.F.; Sherr, C.J.; Cleveland, J.L. Disruption of the ARF-Mdm2-p53 tumor suppressor pathway in Myc-induced lymphomagenesis. Genes Dev 1999, 13, 2658-2669, doi:10.1101/gad.13.20.2658.

13. Vogelstein, B.; Lane, D.; Levine, A.J. Surfing the p53 network. Nature 2000, 408, 307-310, doi:10.1038/35042675.

14. Jain, A.K.; Barton, M.C. p53: emerging roles in stem cells, development and beyond. Development 2018, 145, doi:10.1242/dev.158360

15. Inoue, K.; Kurabayashi, A.; Shuin, T.; Ohtsuki, Y.; Furihata, M. Overexpression of p53 protein in human tumors. Med Mol Morphol 2012, 45, 115-123, doi:10.1007/s00795-012-0575-6.

16. Muller, P.A.; Vousden, K.H. p53 mutations in cancer. Nat Cell Biol 2013, 15, 2-8, doi:10.1038/ncb2641.

17. Cremona, C.A.; Behrens, A. ATM signalling and cancer. Oncogene 2014, 33, 3351-3360, doi:10.1038/onc.2013.275.

18. Levine, A.J.; Oren, M. The first 30 years of p53: growing ever more complex. Nat Rev Cancer 2009, 9, 749-758, doi:10.1038/nrc2723.

19. Mijit, M.; Caracciolo, V.; Melillo, A.; Amicarelli, F.; Giordano, A. Role of p53 in the Regulation of Cellular Senescence. Biomolecules 2020, 10, doi:10.3390/biom10030420.

20. Oren, M.; Bartek, J. The sunny side of p53. Cell 2007, 128, 826-828, doi:10.1016/j.cell.2007.02.027.

21. Vousden, K.H.; Prives, C. Blinded by the Light: The Growing Complexity of p53. Cell 2009, 137, 413-431, doi:10.1016/j.cell.2009.04.037.

22. Gottlieb, E.; Vousden, K.H. p53 regulation of metabolic pathways. Cold Spring Harb Perspect Biol 2010, 2, a001040, doi:10.1101/cshperspect.a001040.

23. Lin, T.; Chao, C.; Saito, S.; Mazur, S.J.; Murphy, M.E.; Appella, E.; Xu, Y. p53 induces differentiation of mouse embryonic stem cells by suppressing Nanog expression. Nat Cell Biol 2005, 7, 165-171, doi:10.1038/ncb1211.

24. Li, M.; He, Y.; Dubois, W.; Wu, X.; Shi, J.; Huang, J. Distinct regulatory mechanisms and functions for p53-activated and p53-repressed DNA damage response genes in embryonic stem cells. Mol Cell 2012, 46, 30-42, doi:10.1016/j.molcel.2012.01.020.

25. Cooks, T.; Harris, C.C.; Oren, M. Caught in the cross fire: p53 in inflammation. Carcinogenesis 2014, 35, 1680-1690, doi:10.1093/carcin/bgu134. 
26. Levine, A.J.; Tomasini, R.; McKeon, F.D.; Mak, T.W.; Melino, G. The p53 family: guardians of maternal reproduction. Nat Rev Mol Cell Biol 2011, 12, 259-265, doi:10.1038/nrm3086.

27. Tyner, S.D.; Venkatachalam, S.; Choi, J.; Jones, S.; Ghebranious, N.; Igelmann, H.; Lu, X.; Soron, G.; Cooper, B.; Brayton, C.; et al. p53 mutant mice that display early ageing-associated phenotypes. Nature 2002, 415, 45-53, doi:10.1038/415045a.

28. Pomerantz, J.H.; Blau, H.M. Tumor suppressors: enhancers or suppressors of regeneration? Development 2013, 140, 25022512, doi:10.1242/dev.084210.

29. Humpton, T.J.; Vousden, K.H. Regulation of Cellular Metabolism and Hypoxia by p53. Cold Spring Harb Perspect Med 2016, 6, doi:10.1101/cshperspect.a026146.

30. Kruiswijk, F.; Labuschagne, C.F.; Vousden, K.H. p53 in survival, death and metabolic health: a lifeguard with a licence to kill. Nat Rev Mol Cell Biol 2015, 16, 393-405, doi:10.1038/nrm4007.

31. Bieging, K.T.; Mello, S.S.; Attardi, L.D. Unravelling mechanisms of p53-mediated tumour suppression. Nat Rev Cancer 2014, 14, 359-370, doi:10.1038/nrc3711.

Fischer, M. Census and evaluation of p53 target genes. Oncogene 2017, 36, 3943-3956, doi:10.1038/onc.2016.502.

33. Pertea, M.; Shumate, A.; Pertea, G.; Varabyou, A.; Breitwieser, F.P.; Chang, Y.C.; Madugundu, A.K.; Pandey, A.; Salzberg, S.L. CHESS: a new human gene catalog curated from thousands of large-scale RNA sequencing experiments reveals extensive transcriptional noise. Genome Biol 2018, 19, 208, doi:10.1186/s13059-018-1590-2.

34. Kunath, T.; Strumpf, D.; Rossant, J. Early trophoblast determination and stem cell maintenance in the mouse--a review. Placenta 2004, 25 Suppl A, S32-38, doi:10.1016/j.placenta.2004.01.015.

35. Cross, J.C. How to make a placenta: mechanisms of trophoblast cell differentiation in mice--a review. Placenta 2005,26 Suppl A, S3-9, doi:10.1016/j.placenta.2005.01.015.

36. Kojima, Y.; Tam, O.H.; Tam, P.P. Timing of developmental events in the early mouse embryo. Semin Cell Dev Biol 2014, 34, 65-75, doi:10.1016/j.semcdb.2014.06.010.

37. Jurisicova, A.; Latham, K.E.; Casper, R.F.; Casper, R.F.; Varmuza, S.L. Expression and regulation of genes associated with cell death during murine preimplantation embryo development. Mol Reprod Dev 1998, 51, 243-253, doi:10.1002/(SICI)1098-2795(199811)51:3<243::AID-MRD3>3.0.CO;2-P.

38. Wells, D.; Bermudez, M.G.; Steuerwald, N.; Thornhill, A.R.; Walker, D.L.; Malter, H.; Delhanty, J.D.; Cohen, J. Expression of genes regulating chromosome segregation, the cell cycle and apoptosis during human preimplantation development. Hum Reprod 2005, 20, 1339-1348, doi:10.1093/humrep/deh778.

39. Choi, J.; Donehower, L.A. p53 in embryonic development: maintaining a fine balance. Cell Mol Life Sci 1999, 55, 38-47, doi:10.1007/s000180050268.

40. Tovy, A.; Spiro, A.; McCarthy, R.; Shipony, Z.; Aylon, Y.; Allton, K.; Ainbinder, E.; Furth, N.; Tanay, A.; Barton, M.; et al . p53 is essential for DNA methylation homeostasis in naive embryonic stem cells, and its loss promotes clonal heterogeneity. Genes Dev 2017, 31, 959-972, doi:10.1101/gad.299198.117.

41. Shin, M.H.; He, Y.; Huang, J. Embryonic stem cells shed new light on the developmental roles of p53. Cell Biosci 2013, 3, 42, doi:10.1186/2045-3701-3-42.

Sah, V.P.; Attardi, L.D.; Mulligan, G.J.; Williams, B.O.; Bronson, R.T.; Jacks, T. A subset of p53-deficient embryos exhibit exencephaly. Nat Genet 1995, 10, 175-180, doi:10.1038/ng0695-175.

43. Armstrong, J.F.; Kaufman, M.H.; Harrison, D.J.; Clarke, A.R. High-frequency developmental abnormalities in p53deficient mice. Curr Biol 1995, 5, 931-936, doi:10.1016/s0960-9822(95)00183-7.

44. Kaufman, M.H.; Kaufman, D.B.; Brune, R.M.; Stark, M.; Armstrong, J.F.; Clarke, A.R. Analysis of fused maxillary incisor dentition in p53-deficient exencephalic mice. J Anat 1997, 191 ( Pt 1), 57-64, doi:10.1046/j.1469-7580.1997.19110057.x. 
45. Rinon, A.; Molchadsky, A.; Nathan, E.; Yovel, G.; Rotter, V.; Sarig, R.; Tzahor, E. p53 coordinates cranial neural crest cell growth and epithelial-mesenchymal transition/delamination processes. Development 2011, 138, 1827-1838, doi:10.1242/dev.053645.

46. Hu, W.; Feng, Z.; Atwal, G.S.; Levine, A.J. p53: a new player in reproduction. Cell Cycle 2008, 7, 848-852, doi:10.4161/cc.7.7.5658.

47. Goh, A.M.; Lim, C.Y.; Chiam, P.C.; Li, L.; Mann, M.B.; Mann, K.M.; Menendez, S.; Lane, D.P. Using targeted transgenic reporter mice to study promoter-specific p53 transcriptional activity. Proc Natl Acad Sci U S A 2012, 109, 1685-1690, doi:10.1073/pnas.1114173109.

48. Norimura, T.; Nomoto, S.; Katsuki, M.; Gondo, Y.; Kondo, S. p53-dependent apoptosis suppresses radiation-induced teratogenesis. Nat Med 1996, 2, 577-580, doi:10.1038/nm0596-577.

49. Wilson, Y.; Morris, I.D.; Kimber, S.J.; Brison, D.R. The role of Trp53 in the mouse embryonic response to DNA damage. Mol Hum Reprod 2019, 25, 397-407, doi:10.1093/molehr/gaz029.

50. Solozobova, V.; Blattner, C. Regulation of p53 in embryonic stem cells. Exp Cell Res 2010, 316, 2434-2446, doi:10.1016/j.yexcr.2010.06.006.

51. Solozobova, V.; Rolletschek, A.; Blattner, C. Nuclear accumulation and activation of p53 in embryonic stem cells after DNA damage. BMC Cell Biol 2009, 10, 46, doi:10.1186/1471-2121-10-46. Setoguchi, K.; TeSlaa, T.; Koehler, C.M.; Teitell, M.A. P53 Regulates Rapid Apoptosis in Human Pluripotent Stem Cells. J Mol Biol 2016, 428, 1465-1475, doi:10.1016/j.jmb.2015.07.019.

53. Han, M.K.; Song, E.K.; Guo, Y.; Ou, X.; Mantel, C.; Broxmeyer, H.E. SIRT1 regulates apoptosis and Nanog expression in mouse embryonic stem cells by controlling p53 subcellular localization. Cell Stem Cell 2008, 2, 241-251, doi:10.1016/j.stem.2008.01.002.

54. Lee, D.F.; Su, J.; Ang, Y.S.; Carvajal-Vergara, X.; Mulero-Navarro, S.; Pereira, C.F.; Gingold, J.; Wang, H.L.; Zhao, R.; Sevilla, A.; et al. Regulation of embryonic and induced pluripotency by aurora kinase-p53 signaling. Cell Stem Cell 2012 , 11, 179-194, doi:10.1016/j.stem.2012.05.020.

55. Maimets, T.; Neganova, I.; Armstrong, L.; Lako, M. Activation of p53 by nutlin leads to rapid differentiation of human embryonic stem cells. Oncogene 2008, 27, 5277-5287, doi:10.1038/onc.2008.166.

56. Suvorova, II; Grigorash, B.B.; Chuykin, I.A.; Pospelova, T.V.; Pospelov, V.A. G1 checkpoint is compromised in mouse ESCs due to functional uncoupling of p53-p21Waf1 signaling. Cell Cycle 2016, 15, 52-63, doi:10.1080/15384101.2015.1120927.

Klein, A.M.; de Queiroz, R.M.; Venkatesh, D.; Prives, C. The roles and regulation of MDM2 and MDMX: it is not just about p53. Genes Dev 2021, 35, 575-601, doi:10.1101/gad.347872.120.

58. Ivanov, G.S.; Ivanova, T.; Kurash, J.; Ivanov, A.; Chuikov, S.; Gizatullin, F.; Herrera-Medina, E.M.; Rauscher, F., 3rd; Reinberg, D.; Barlev, N.A. Methylation-acetylation interplay activates p53 in response to DNA damage. Mol Cell Biol 2007, 27, 6756-6769, doi:10.1128/MCB.00460-07.

59. Kruse, J.P.; Gu, W. Modes of p53 regulation. Cell 2009, 137, 609-622, doi:10.1016/j.cell.2009.04.050.

60. Hull, R.; Oosthuysen, B.; Cajee, U.F.; Mokgohloa, L.; Nweke, E.; Antunes, R.J.; Coetzer, T.H.; Ntwasa, M. The Drosophila retinoblastoma binding protein 6 family member has two isoforms and is potentially involved in embryonic patterning. Int J Mol Sci 2015, 16, 10242-10266, doi:10.3390/ijms160510242.

61. Li, L.; Deng, B.; Xing, G.; Teng, Y.; Tian, C.; Cheng, X.; Yin, X.; Yang, J.; Gao, X.; Zhu, Y.; et al. PACT is a negative regulator of p53 and essential for cell growth and embryonic development. Proc Natl Acad Sci U S A 2007, 104, 7951-7956, doi:10.1073/pnas.0701916104. 
62. Yang, X.; Zhang, Q.; Yang, X.; Zhao, M.; Yang, T.; Yao, A.; Tian, X. PACT cessation overcomes ovarian cancer cell chemoresistance to cisplatin by enhancing p53-mediated apoptotic pathway. Biochem Biophys Res Commun 2019, 511, 719-724, doi:10.1016/j.bbrc.2019.02.089.

63. Bennett, R.L.; Pan, Y.; Christian, J.; Hui, T.; May, W.S., Jr. The RAX/PACT-PKR stress response pathway promotes p53 sumoylation and activation, leading to G(1) arrest. Cell Cycle 2012, 11, 407-417, doi:10.4161/cc.11.2.18999.

64. Fujitani, K.; Otomo, A.; Nagayama, Y.; Tachibana, T.; Kato, R.; Kawashima, Y.; Kodera, Y.; Kato, T.; Takada, S.; Tamura, K.; et al. PACT/PRKRA and p53 regulate transcriptional activity of DMRT1. Genet Mol Biol 2020, 43, e20190017, doi:10.1590/1678-4685-GMB-2019-0017.

65. Bardot, E.S.; Hadjantonakis, A.K. Mouse gastrulation: Coordination of tissue patterning, specification and diversification of cell fate. Mech Dev 2020, 163, 103617, doi:10.1016/j.mod.2020.103617.

66. Jones, S.N.; Roe, A.E.; Donehower, L.A.; Bradley, A. Rescue of embryonic lethality in Mdm2-deficient mice by absence of p53. Nature 1995, 378, 206-208, doi:10.1038/378206a0.

67. Montes de Oca Luna, R.; Wagner, D.S.; Lozano, G. Rescue of early embryonic lethality in mdm2-deficient mice by deletion of p53. Nature 1995, 378, 203-206, doi:10.1038/378203a0.

68. Jones, S.N.; Sands, A.T.; Hancock, A.R.; Vogel, H.; Donehower, L.A.; Linke, S.P.; Wahl, G.M.; Bradley, A. The tumorigenic potential and cell growth characteristics of p53-deficient cells are equivalent in the presence or absence of Mdm2. Proc Natl Acad Sci U S A 1996, 93, 14106-14111, doi:10.1073/pnas.93.24.14106.

69. McMasters, K.M.; Montes de Oca Luna, R.; Pena, J.R.; Lozano, G. mdm2 deletion does not alter growth characteristics of p53-deficient embryo fibroblasts. Oncogene 1996, 13, 1731-1736.

70. Migliorini, D.; Lazzerini Denchi, E.; Danovi, D.; Jochemsen, A.; Capillo, M.; Gobbi, A.; Helin, K.; Pelicci, P.G.; Marine, J.C. $\operatorname{Mdm} 4(\mathrm{Mdmx})$ regulates p53-induced growth arrest and neuronal cell death during early embryonic mouse development. Mol Cell Biol 2002, 22, 5527-5538, doi:10.1128/MCB.22.15.5527-5538.2002.

71. Finch, R.A.; Donoviel, D.B.; Potter, D.; Shi, M.; Fan, A.; Freed, D.D.; Wang, C.Y.; Zambrowicz, B.P.; Ramirez-Solis, R.; Sands, A.T.; et al. mdmx is a negative regulator of p53 activity in vivo. Cancer Res 2002, 62, 3221-3225. Parant, J.; Chavez-Reyes, A.; Little, N.A.; Yan, W.; Reinke, V.; Jochemsen, A.G.; Lozano, G. Rescue of embryonic lethality in Mdm4-null mice by loss of Trp53 suggests a nonoverlapping pathway with MDM2 to regulate p53. Nat Genet 2001, 29, 92-95, doi:10.1038/ng714.

73. Chavez-Reyes, A.; Parant, J.M.; Amelse, L.L.; de Oca Luna, R.M.; Korsmeyer, S.J.; Lozano, G. Switching mechanisms of cell death in mdm2- and mdm4-null mice by deletion of p53 downstream targets. Cancer Res 2003, 63, 8664-8669.

74. Aylon, Y.; Oren, M. p53: guardian of ploidy. Mol Oncol 2011, 5, 315-323, doi:10.1016/j.molonc.2011.07.007.

75. Vassilev, A.; DePamphilis, M.L. Links between DNA Replication, Stem Cells and Cancer. Genes (Basel) 2017, 8, doi:10.3390/genes8020045.

76. Khan, S.H.; Wahl, G.M. p53 and pRb prevent rereplication in response to microtubule inhibitors by mediating a reversible G1 arrest. Cancer Res 1998, 58, 396-401.

77. Lanni, J.S.; Jacks, T. Characterization of the p53-dependent postmitotic checkpoint following spindle disruption. Mol Cell Biol 1998, 18, 1055-1064, doi:10.1128/MCB.18.2.1055.

78. Schvartzman, J.M.; Duijf, P.H.; Sotillo, R.; Coker, C.; Benezra, R. Mad2 is a critical mediator of the chromosome instability observed upon Rb and p53 pathway inhibition. Cancer Cell 2011, 19, 701-714, doi:10.1016/j.ccr.2011.04.017.

79. Vitale, I.; Senovilla, L.; Jemaa, M.; Michaud, M.; Galluzzi, L.; Kepp, O.; Nanty, L.; Criollo, A.; Rello-Varona, S.; Manic, G.; et al. Multipolar mitosis of tetraploid cells: inhibition by p53 and dependency on Mos. EMBO J 2010, 29, 1272-1284, doi:10.1038/emboj.2010.11. 
80. Li, M.; Fang, X.; Baker, D.J.; Guo, L.; Gao, X.; Wei, Z.; Han, S.; van Deursen, J.M.; Zhang, P. The ATM-p53 pathway suppresses aneuploidy-induced tumorigenesis. Proc Natl Acad Sci U S A 2010, 107, 14188-14193, doi:10.1073/pnas.1005960107.

81. Adler-Wailes, D.C.; Kramer, J.A.; DePamphilis, M.L. Geminin Is Essential for Pluripotent Cell Viability During Teratoma Formation, but Not for Differentiated Cell Viability During Teratoma Expansion. Stem Cells Dev 2017, 26, 285-302, doi:10.1089/scd.2016.0260.

Rivlin, N.; Katz, S.; Doody, M.; Sheffer, M.; Horesh, S.; Molchadsky, A.; Koifman, G.; Shetzer, Y.; Goldfinger, N.; Rotter, V.; et al. Rescue of embryonic stem cells from cellular transformation by proteomic stabilization of mutant p53 and conversion into WT conformation. Proc Natl Acad Sci U S A 2014, 111, 7006-7011, doi:10.1073/pnas.1320428111.

83. Benedict, B.; van Harn, T.; Dekker, M.; Hermsen, S.; Kucukosmanoglu, A.; Pieters, W.; Delzenne-Goette, E.; Dorsman, J.C.; Petermann, E.; Foijer, F.; et al. Loss of p53 suppresses replication-stress-induced DNA breakage in G1/S checkpoint deficient cells. Elife 2018, 7, doi:10.7554/eLife.37868.

84. Shigeta, M.; Ohtsuka, S.; Nishikawa-Torikai, S.; Yamane, M.; Fujii, S.; Murakami, K.; Niwa, H. Maintenance of pluripotency in mouse ES cells without Trp53. Sci Rep 2013, 3, 2944, doi:10.1038/srep02944.

85. Li, Y.; Huang, C.; Zha, L.; Kong, M.; Yang, Q.; Zhu, Y.; Peng, Y.; Ouyang, Q.; Lu, G.; Lin, G.; et al. Generation of NERCe003-A-3, a p53 compound heterozygous mutation human embryonic stem cell line, by CRISPR/Cas9 editing. Stem Cell Res 2019, 34, 101371, doi:10.1016/j.scr.2018.101371.

86. Harvey, M.; Sands, A.T.; Weiss, R.S.; Hegi, M.E.; Wiseman, R.W.; Pantazis, P.; Giovanella, B.C.; Tainsky, M.A.; Bradley, A.; Donehower, L.A. In vitro growth characteristics of embryo fibroblasts isolated from p53-deficient mice. Oncogene 1993, 8, 2457-2467.

87. Duensing, A.; Duensing, S. Guilt by association? p53 and the development of aneuploidy in cancer. Biochem Biophys Res Commun 2005, 331, 694-700, doi:10.1016/j.bbrc.2005.03.157.

88. Mora, P.T.; Chandrasekaran, K.; McFarland, V.W. An embryo protein induced by SV40 virus transformation of mouse cells. Nature 1980, 288, 722-724, doi:10.1038/288722a0.

89. Rogel, A.; Popliker, M.; Webb, C.G.; Oren, M. p53 cellular tumor antigen: analysis of mRNA levels in normal adult tissues, embryos, and tumors. Mol Cell Biol 1985, 5, 2851-2855, doi:10.1128/mcb.5.10.2851-2855.1985.

90. Schmid, P.; Lorenz, A.; Hameister, H.; Montenarh, M. Expression of p53 during mouse embryogenesis. Development 1991, $113,857-865$.

91. Abdelalim, E.M.; Tooyama, I. The p53 inhibitor, pifithrin-alpha, suppresses self-renewal of embryonic stem cells. Biochem Biophys Res Commun 2012, 420, 605-610, doi:10.1016/j.bbrc.2012.03.041.

92. Zhu, J.; Singh, M.; Selivanova, G.; Peuget, S. Pifithrin-alpha alters p53 post-translational modifications pattern and differentially inhibits p53 target genes. Sci Rep 2020, 10, 1049, doi:10.1038/s41598-020-58051-1.

93. Boyer, L.A.; Lee, T.I.; Cole, M.F.; Johnstone, S.E.; Levine, S.S.; Zucker, J.P.; Guenther, M.G.; Kumar, R.M.; Murray, H.L.; Jenner, R.G.; et al. Core transcriptional regulatory circuitry in human embryonic stem cells. Cell 2005, 122, 947-956, doi:10.1016/j.cell.2005.08.020.

94. Chen, X.; Xu, H.; Yuan, P.; Fang, F.; Huss, M.; Vega, V.B.; Wong, E.; Orlov, Y.L.; Zhang, W.; Jiang, J.; et al. Integration of external signaling pathways with the core transcriptional network in embryonic stem cells. Cell 2008, 133, 1106-1117, doi:10.1016/j.cell.2008.04.043.

95. Cole, M.F.; Johnstone, S.E.; Newman, J.J.; Kagey, M.H.; Young, R.A. Tcf3 is an integral component of the core regulatory circuitry of embryonic stem cells. Genes Dev 2008, 22, 746-755, doi:10.1101/gad.1642408.

96. Yi, F.; Pereira, L.; Merrill, B.J. Tcf3 functions as a steady-state limiter of transcriptional programs of mouse embryonic stem cell self-renewal. Stem Cells 2008, 26, 1951-1960, doi:10.1634/stemcells.2008-0229.

97. Young, R.A. Control of the embryonic stem cell state. Cell 2011, 144, 940-954, doi:10.1016/j.cell.2011.01.032. 
98. Ho, J.S.; Ma, W.; Mao, D.Y.; Benchimol, S. p53-Dependent transcriptional repression of c-myc is required for G1 cell cycle arrest. Mol Cell Biol 2005, 25, 7423-7431, doi:10.1128/MCB.25.17.7423-7431.2005.

99. Jain, A.K.; Barton, M.C. Making sense of ubiquitin ligases that regulate p53. Cancer Biol Ther 2010, 10, 665-672, doi:10.4161/cbt.10.7.13445.

100. Jain, A.K.; Allton, K.; Iacovino, M.; Mahen, E.; Milczarek, R.J.; Zwaka, T.P.; Kyba, M.; Barton, M.C. p53 regulates cell cycle and microRNAs to promote differentiation of human embryonic stem cells. PLoS Biol 2012, 10, e1001268, doi:10.1371/journal.pbio.1001268.

101. Zhang, Z.N.; Chung, S.K.; Xu, Z.; Xu, Y. Oct4 maintains the pluripotency of human embryonic stem cells by inactivating p53 through Sirt1-mediated deacetylation. Stem Cells 2014, 32, 157-165, doi:10.1002/stem.1532.

102. Fatica, A.; Bozzoni, I. Long non-coding RNAs: new players in cell differentiation and development. Nat Rev Genet 2014, 15, 7-21, doi:10.1038/nrg3606.

103. Rinn, J.L. lncRNAs: linking RNA to chromatin. Cold Spring Harb Perspect Biol 2014, 6, doi:10.1101/cshperspect.a018614.

104. Jain, A.K.; Xi, Y.; McCarthy, R.; Allton, K.; Akdemir, K.C.; Patel, L.R.; Aronow, B.; Lin, C.; Li, W.; Yang, L.; et al. LncPRESS1 Is a p53-Regulated LncRNA that Safeguards Pluripotency by Disrupting SIRT6-Mediated De-acetylation of Histone H3K56. Mol Cell 2016, 64, 967-981, doi:10.1016/j.molcel.2016.10.039.

105. Xie, W.; Song, C.; Young, N.L.; Sperling, A.S.; Xu, F.; Sridharan, R.; Conway, A.E.; Garcia, B.A.; Plath, K.; Clark, A.T.; et al. Histone h3 lysine 56 acetylation is linked to the core transcriptional network in human embryonic stem cells. Mol Cell 2009, 33, 417-427, doi:10.1016/j.molcel.2009.02.004.

106. Lin, N.; Chang, K.Y.; Li, Z.; Gates, K.; Rana, Z.A.; Dang, J.; Zhang, D.; Han, T.; Yang, C.S.; Cunningham, T.J.; et al. An evolutionarily conserved long noncoding RNA TUNA controls pluripotency and neural lineage commitment. Mol Cell 2014, 53, 1005-1019, doi:10.1016/j.molcel.2014.01.021.

107. Lee, K.H.; Li, M.; Michalowski, A.M.; Zhang, X.; Liao, H.; Chen, L.; Xu, Y.; Wu, X.; Huang, J. A genomewide study identifies the Wnt signaling pathway as a major target of p53 in murine embryonic stem cells. Proc Natl Acad Sci U S A 2010, 107, 69-74, doi:10.1073/pnas.0909734107.

108. Hu, W.; Feng, Z.; Teresky, A.K.; Levine, A.J. p53 regulates maternal reproduction through LIF. Nature 2007, 450, 721-724, doi:10.1038/nature05993.

109. Dravid, G.; Ye, Z.; Hammond, H.; Chen, G.; Pyle, A.; Donovan, P.; Yu, X.; Cheng, L. Defining the role of Wnt/beta-catenin signaling in the survival, proliferation, and self-renewal of human embryonic stem cells. Stem Cells 2005, 23, 1489-1501, doi:10.1634/stemcells.2005-0034.

110. Ogawa, K.; Nishinakamura, R.; Iwamatsu, Y.; Shimosato, D.; Niwa, H. Synergistic action of Wnt and LIF in maintaining pluripotency of mouse ES cells. Biochem Biophys Res Commun 2006, 343, 159-166, doi:10.1016/j.bbrc.2006.02.127.

111. Huntzinger, E.; Izaurralde, E. Gene silencing by microRNAs: contributions of translational repression and mRNA decay. Nat Rev Genet 2011, 12, 99-110, doi:10.1038/nrg2936.

112. Wang, Y.; Melton, C.; Li, Y.P.; Shenoy, A.; Zhang, X.X.; Subramanyam, D.; Blelloch, R. miR-294/miR-302 promotes proliferation, suppresses G1-S restriction point, and inhibits ESC differentiation through separable mechanisms. Cell Rep 2013, 4, 99-109, doi:10.1016/j.celrep.2013.05.027.

113. Liu, Z.; Zhang, C.; Skamagki, M.; Khodadadi-Jamayran, A.; Zhang, W.; Kong, D.; Chang, C.W.; Feng, J.; Han, X.; Townes, T.M.; et al. Elevated p53 Activities Restrict Differentiation Potential of MicroRNA-Deficient Pluripotent Stem Cells. Stem Cell Reports 2017, 9, 1604-1617, doi:10.1016/j.stemcr.2017.10.006.

114. Ungewitter, E.; Scrable, H. Delta40p53 controls the switch from pluripotency to differentiation by regulating IGF signaling in ESCs. Genes Dev 2010, 24, 2408-2419, doi:10.1101/gad.1987810. 
115. Courtois, S.; Verhaegh, G.; North, S.; Luciani, M.G.; Lassus, P.; Hibner, U.; Oren, M.; Hainaut, P. DeltaN-p53, a natural isoform of p53 lacking the first transactivation domain, counteracts growth suppression by wild-type p53. Oncogene 2002, 21, 6722-6728, doi:10.1038/sj.onc.1205874.

116. Zhu, J.; Zhou, W.; Jiang, J.; Chen, X. Identification of a novel p53 functional domain that is necessary for mediating apoptosis. J Biol Chem 1998, 273, 13030-13036, doi:10.1074/jbc.273.21.13030.

117. Ghosh, A.; Stewart, D.; Matlashewski, G. Regulation of human p53 activity and cell localization by alternative splicing. Mol Cell Biol 2004, 24, 7987-7997, doi:10.1128/MCB.24.18.7987-7997.2004.

118. Bendall, S.C.; Stewart, M.H.; Menendez, P.; George, D.; Vijayaragavan, K.; Werbowetski-Ogilvie, T.; Ramos-Mejia, V.; Rouleau, A.; Yang, J.; Bosse, M.; et al. IGF and FGF cooperatively establish the regulatory stem cell niche of pluripotent human cells in vitro. Nature 2007, 448, 1015-1021, doi:10.1038/nature06027.

119. Hanna, J.; Saha, K.; Pando, B.; van Zon, J.; Lengner, C.J.; Creyghton, M.P.; van Oudenaarden, A.; Jaenisch, R. Direct cell reprogramming is a stochastic process amenable to acceleration. Nature 2009, 462, 595-601, doi:10.1038/nature08592.

120. Lin, Y.; Cheng, Z.; Yang, Z.; Zheng, J.; Lin, T. DNp73 improves generation efficiency of human induced pluripotent stem cells. BMC Cell Biol 2012, 13, 9, doi:10.1186/1471-2121-13-9.

121. Fatt, M.P.; Cancino, G.I.; Miller, F.D.; Kaplan, D.R. p63 and p73 coordinate p53 function to determine the balance between survival, cell death, and senescence in adult neural precursor cells. Cell Death Differ 2014, 21, 1546-1559, doi:10.1038/cdd.2014.61.

122. Zhao, Y.; Yin, X.; Qin, H.; Zhu, F.; Liu, H.; Yang, W.; Zhang, Q.; Xiang, C.; Hou, P.; Song, Z.; et al. Two supporting factors greatly improve the efficiency of human iPSC generation. Cell Stem Cell 2008, 3, 475-479, doi:10.1016/j.stem.2008.10.002.

123. Kawamura, T.; Suzuki, J.; Wang, Y.V.; Menendez, S.; Morera, L.B.; Raya, A.; Wahl, G.M.; Izpisua Belmonte, J.C. Linking the p53 tumour suppressor pathway to somatic cell reprogramming. Nature 2009, 460, 1140-1144, doi:10.1038/nature08311.

124. Marion, R.M.; Strati, K.; Li, H.; Murga, M.; Blanco, R.; Ortega, S.; Fernandez-Capetillo, O.; Serrano, M.; Blasco, M.A. A p53mediated DNA damage response limits reprogramming to ensure iPS cell genomic integrity. Nature 2009, 460, 1149-1153, doi:10.1038/nature08287.

125. Hong, H.; Takahashi, K.; Ichisaka, T.; Aoi, T.; Kanagawa, O.; Nakagawa, M.; Okita, K.; Yamanaka, S. Suppression of induced pluripotent stem cell generation by the p53-p21 pathway. Nature 2009, 460, 1132-1135, doi:10.1038/nature08235.

126. Jaiswal, S.K.; Oh, J.J.; DePamphilis, M.L. Cell cycle arrest and apoptosis are not dependent on p53 prior to p53-dependent embryonic stem cell differentiation. Stem Cells 2020, 38, 1091-1106, doi:10.1002/stem.3199.

127. Keller, G.M. In vitro differentiation of embryonic stem cells. Curr Opin Cell Biol 1995, 7, 862-869, doi:10.1016/09550674(95)80071-9.

128. Boheler, K.R.; Czyz, J.; Tweedie, D.; Yang, H.T.; Anisimov, S.V.; Wobus, A.M. Differentiation of pluripotent embryonic stem cells into cardiomyocytes. Circ Res 2002, 91, 189-201, doi:10.1161/01.res.0000027865.61704.32.

129. Qin, H.; Yu, T.; Qing, T.; Liu, Y.; Zhao, Y.; Cai, J.; Li, J.; Song, Z.; Qu, X.; Zhou, P.; et al. Regulation of apoptosis and differentiation by p53 in human embryonic stem cells. J Biol Chem 2007, 282, 5842-5852, doi:10.1074/jbc.M610464200.

130. Xu, Y. A new role for p53 in maintaining genetic stability in embryonic stem cells. Cell Cycle 2005, 4, 363-364, doi:10.4161/cc.4.3.1529.

131. Hassig, C.A.; Fleischer, T.C.; Billin, A.N.; Schreiber, S.L.; Ayer, D.E. Histone deacetylase activity is required for full transcriptional repression by mSin3A. Cell 1997, 89, 341-347, doi:10.1016/s0092-8674(00)80214-7.

132. Xin, M.; Davis, C.A.; Molkentin, J.D.; Lien, C.L.; Duncan, S.A.; Richardson, J.A.; Olson, E.N. A threshold of GATA4 and GATA6 expression is required for cardiovascular development. Proc Natl Acad Sci U S A 2006, 103, 11189-11194, doi:10.1073/pnas.0604604103. 
133. Yu, J.; Vodyanik, M.A.; Smuga-Otto, K.; Antosiewicz-Bourget, J.; Frane, J.L.; Tian, S.; Nie, J.; Jonsdottir, G.A.; Ruotti, V.; Stewart, R.; et al. Induced pluripotent stem cell lines derived from human somatic cells. Science 2007, 318, 1917-1920, doi:10.1126/science.1151526.

134. Pelengaris, S.; Khan, M.; Evan, G. c-MYC: more than just a matter of life and death. Nat Rev Cancer 2002, 2, 764-776, doi:10.1038/nrc904.

135. Krizhanovsky, V.; Lowe, S.W. Stem cells: The promises and perils of p53. Nature 2009, 460, 1085-1086, doi:10.1038/4601085a.

136. Kaufman, M.H. Chromosome analysis of early postimplantation presumptive haploid parthenogenetic mouse embryos. J Embryol Exp Morphol 1978, 45, 85-91.

137. Keller, G. Embryonic stem cell differentiation: emergence of a new era in biology and medicine. Genes Dev 2005, 19, 11291155, doi:10.1101/gad.1303605.

138. Niwa, H. Mouse ES cell culture system as a model of development. Dev Growth Differ 2010, 52, 275-283, doi:10.1111/j.1440-169X.2009.01166.x.

139. Sagi, I.; Chia, G.; Golan-Lev, T.; Peretz, M.; Weissbein, U.; Sui, L.; Sauer, M.V.; Yanuka, O.; Egli, D.; Benvenisty, N. Derivation and differentiation of haploid human embryonic stem cells. Nature 2016, 532, 107-111, doi:10.1038/nature17408.

140. Samanta, M.; Kalantry, S. Generating primed pluripotent epiblast stem cells: A methodology chapter. Curr Top Dev Biol 2020, 138, 139-174, doi:10.1016/bs.ctdb.2020.01.005.

141. Mulas, C.; Kalkan, T.; von Meyenn, F.; Leitch, H.G.; Nichols, J.; Smith, A. Defined conditions for propagation and manipulation of mouse embryonic stem cells. Development 2019, 146, doi:10.1242/dev.173146.

142. Smith, A. Formative pluripotency: the executive phase in a developmental continuum. Development 2017, 144, 365-373, doi:10.1242/dev.142679.

143. Ying, Q.L.; Wray, J.; Nichols, J.; Batlle-Morera, L.; Doble, B.; Woodgett, J.; Cohen, P.; Smith, A. The ground state of embryonic stem cell self-renewal. Nature 2008, 453, 519-523, doi:10.1038/nature06968.

144. Alexandrova, S.; Kalkan, T.; Humphreys, P.; Riddell, A.; Scognamiglio, R.; Trumpp, A.; Nichols, J. Selection and dynamics of embryonic stem cell integration into early mouse embryos. Development 2016, 143, 24-34, doi:10.1242/dev.124602.

145. Kojima, Y.; Kaufman-Francis, K.; Studdert, J.B.; Steiner, K.A.; Power, M.D.; Loebel, D.A.; Jones, V.; Hor, A.; de Alencastro, G.; Logan, G.J.; et al. The transcriptional and functional properties of mouse epiblast stem cells resemble the anterior primitive streak. Cell Stem Cell 2014, 14, 107-120, doi:10.1016/j.stem.2013.09.014.

146. Gayen, S.; Maclary, E.; Buttigieg, E.; Hinten, M.; Kalantry, S. A Primary Role for the Tsix lncRNA in Maintaining Random X-Chromosome Inactivation. Cell Rep 2015, 11, 1251-1265, doi:10.1016/j.celrep.2015.04.039.

147. Sarkar, M.K.; Gayen, S.; Kumar, S.; Maclary, E.; Buttigieg, E.; Hinten, M.; Kumari, A.; Harris, C.; Sado, T.; Kalantry, S. An Xist-activating antisense RNA required for X-chromosome inactivation. Nat Commun 2015, 6, 8564, doi:10.1038/ncomms9564.

148. Barnaba, N.; LaRocque, J.R. Targeting cell cycle regulation via the G2-M checkpoint for synthetic lethality in melanoma. Cell Cycle 2021, 20, 1041-1051, doi:10.1080/15384101.2021.1922806.

149. Stark, G.R.; Taylor, W.R. Analyzing the G2/M checkpoint. Methods Mol Biol 2004, 280, 51-82, doi:10.1385/1-59259-7882:051.

150. He, H.; Wang, C.; Dai, Q.; Li, F.; Bergholz, J.; Li, Z.; Li, Q.; Xiao, Z.X. p53 and p73 Regulate Apoptosis but Not Cell-Cycle Progression in Mouse Embryonic Stem Cells upon DNA Damage and Differentiation. Stem Cell Reports 2016, 7, 10871098, doi:10.1016/j.stemcr.2016.10.008.

151. Prost, S.; Bellamy, C.O.; Clarke, A.R.; Wyllie, A.H.; Harrison, D.J. p53-independent DNA repair and cell cycle arrest in embryonic stem cells. FEBS Lett 1998, 425, 499-504, doi:10.1016/s0014-5793(98)00296-8. 
152. Hume, S.; Dianov, G.L.; Ramadan, K. A unified model for the G1/S cell cycle transition. Nucleic Acids Res 2020, 48, 1248312501, doi:10.1093/nar/gkaa1002.

153. Aladjem, M.I.; Spike, B.T.; Rodewald, L.W.; Hope, T.J.; Klemm, M.; Jaenisch, R.; Wahl, G.M. ES cells do not activate p53dependent stress responses and undergo p53-independent apoptosis in response to DNA damage. Curr Biol 1998, 8, 145155.

154. Hong, Y.; Stambrook, P.J. Restoration of an absent G1 arrest and protection from apoptosis in embryonic stem cells after ionizing radiation. Proc Natl Acad Sci U S A 2004, 101, 14443-14448, doi:10.1073/pnas.0401346101.

155. Li, M.; Gou, H.; Tripathi, B.K.; Huang, J.; Jiang, S.; Dubois, W.; Waybright, T.; Lei, M.; Shi, J.; Zhou, M.; et al. An Apela RNA-Containing Negative Feedback Loop Regulates p53-Mediated Apoptosis in Embryonic Stem Cells. Cell Stem Cell 2015, 16, 669-683, doi:10.1016/j.stem.2015.04.002.

156. Ter Huurne, M.; Peng, T.; Yi, G.; van Mierlo, G.; Marks, H.; Stunnenberg, H.G. Critical Role for P53 in Regulating the Cell Cycle of Ground State Embryonic Stem Cells. Stem Cell Reports 2020, 14, 175-183, doi:10.1016/j.stemcr.2020.01.001.

157. Ter Huurne, M.; Chappell, J.; Dalton, S.; Stunnenberg, H.G. Distinct Cell-Cycle Control in Two Different States of Mouse Pluripotency. Cell Stem Cell 2017, 21, 449-455 e444, doi:10.1016/j.stem.2017.09.004.

158. Corbet, S.W.; Clarke, A.R.; Gledhill, S.; Wyllie, A.H. P53-dependent and -independent links between DNA-damage, apoptosis and mutation frequency in ES cells. Oncogene 1999, 18, 1537-1544, doi:10.1038/sj.onc.1202436.

159. de Vries, A.; Flores, E.R.; Miranda, B.; Hsieh, H.M.; van Oostrom, C.T.; Sage, J.; Jacks, T. Targeted point mutations of p53 lead to dominant-negative inhibition of wild-type p53 function. Proc Natl Acad Sci U S A 2002, 99, 2948-2953, doi:10.1073/pnas.052713099.

160. Grandela, C.; Pera, M.F.; Grimmond, S.M.; Kolle, G.; Wolvetang, E.J. p53 is required for etoposide-induced apoptosis of human embryonic stem cells. Stem Cell Res 2007, 1, 116-128, doi:10.1016/j.scr.2007.10.003.

161. Atashpaz, S.; Samadi Shams, S.; Gonzalez, J.M.; Sebestyen, E.; Arghavanifard, N.; Gnocchi, A.; Albers, E.; Minardi, S.; Faga, G.; Soffientini, P.; et al. ATR expands embryonic stem cell fate potential in response to replication stress. Elife 2020, 9, doi:10.7554/eLife.54756.

162. Grow, E.J.; Weaver, B.D.; Smith, C.M.; Guo, J.; Stein, P.; Shadle, S.C.; Hendrickson, P.G.; Johnson, N.E.; Butterfield, R.J.; Menafra, R.; et al. p53 convergently activates Dux/DUX4 in embryonic stem cells and in facioscapulohumeral muscular dystrophy cell models. Nat Genet 2021, doi:10.1038/s41588-021-00893-0.

163. Mansouri, A.; Fukumitsu, H.; Schindehuette, J.; Krieglstein, K. Differentiation of embryonic stem cells. Curr Protoc Neurosci 2009, Chapter 3, Unit3 6, doi:10.1002/0471142301.ns0306s47.

164. Rivlin, N.; Brosh, R.; Oren, M.; Rotter, V. Mutations in the p53 Tumor Suppressor Gene: Important Milestones at the Various Steps of Tumorigenesis. Genes Cancer 2011, 2, 466-474, doi:10.1177/1947601911408889.

165. Jacobs, K.; Zambelli, F.; Mertzanidou, A.; Smolders, I.; Geens, M.; Nguyen, H.T.; Barbe, L.; Sermon, K.; Spits, C. HigherDensity Culture in Human Embryonic Stem Cells Results in DNA Damage and Genome Instability. Stem Cell Reports 2016, 6, 330-341, doi:10.1016/j.stemcr.2016.01.015.

166. Deng, Y.; Chan, S.S.; Chang, S. Telomere dysfunction and tumour suppression: the senescence connection. Nat Rev Cancer 2008, 8, 450-458, doi:10.1038/nrc2393.

167. Di Micco, R.; Cicalese, A.; Fumagalli, M.; Dobreva, M.; Verrecchia, A.; Pelicci, P.G.; di Fagagna, F. DNA damage response activation in mouse embryonic fibroblasts undergoing replicative senescence and following spontaneous immortalization. Cell Cycle 2008, 7, 3601-3606, doi:10.4161/cc.7.22.7152.

168. Campisi, J.; d'Adda di Fagagna, F. Cellular senescence: when bad things happen to good cells. Nat Rev Mol Cell Biol 2007, 8, 729-740, doi:10.1038/nrm2233.

169. Serrano, M.; Lin, A.W.; McCurrach, M.E.; Beach, D.; Lowe, S.W. Oncogenic ras provokes premature cell senescence associated with accumulation of p53 and p16INK4a. Cell 1997, 88, 593-602, doi:10.1016/s0092-8674(00)81902-9. 
170. Blagosklonny, M.V. Cell cycle arrest is not yet senescence, which is not just cell cycle arrest: terminology for TOR-driven aging. Aging (Albany NY) 2012, 4, 159-165, doi:10.18632/aging.100443.

171. Lowe, S.W.; Ruley, H.E.; Jacks, T.; Housman, D.E. p53-dependent apoptosis modulates the cytotoxicity of anticancer agents. Cell 1993, 74, 957-967, doi:10.1016/0092-8674(93)90719-7.

172. de Rozieres, S.; Maya, R.; Oren, M.; Lozano, G. The loss of mdm2 induces p53-mediated apoptosis. Oncogene 2000, 19, 1691-1697, doi:10.1038/sj.onc.1203468.

173. Lowe, S.W.; Bodis, S.; McClatchey, A.; Remington, L.; Ruley, H.E.; Fisher, D.E.; Housman, D.E.; Jacks, T. p53 status and the efficacy of cancer therapy in vivo. Science 1994, 266, 807-810, doi:10.1126/science.7973635.

174. Lowe, S.W.; Jacks, T.; Housman, D.E.; Ruley, H.E. Abrogation of oncogene-associated apoptosis allows transformation of p53-deficient cells. Proc Natl Acad Sci U S A 1994, 91, 2026-2030, doi:10.1073/pnas.91.6.2026.

175. Vater, C.A.; Bartle, L.M.; Dionne, C.A.; Littlewood, T.D.; Goldmacher, V.S. Induction of apoptosis by tamoxifen-activation of a p53-estrogen receptor fusion protein expressed in E1A and T24 H-ras transformed p53-/- mouse embryo fibroblasts. Oncogene 1996, 13, 739-748.

176. Samuelson, A.V.; Lowe, S.W. Selective induction of p53 and chemosensitivity in RB-deficient cells by E1A mutants unable to bind the RB-related proteins. Proc Natl Acad Sci U S A 1997, 94, 12094-12099, doi:10.1073/pnas.94.22.12094.

177. Hermeking, H.; Eick, D. Mediation of c-Myc-induced apoptosis by p53. Science 1994, 265, 2091-2093, doi:10.1126/science.8091232.

178. Hosogane, M.; Bosu, L.; Fukumoto, E.; Yamada, H.; Sato, S.; Nakayama, K. Geminin is an indispensable inhibitor of Cdt1 in mouse embryonic stem cells. Genes Cells 2017, 22, 360-375, doi:10.1111/gtc.12482.

179. Huang, Y.Y.; Kaneko, K.J.; Pan, H.; DePamphilis, M.L. Geminin is Essential to Prevent DNA Re-Replication-Dependent Apoptosis in Pluripotent Cells, but not in Differentiated Cells. Stem Cells 2015, 33, 3239-3253, doi:10.1002/stem.2092.

180. Iliou, M.S.; Kotantaki, P.; Karamitros, D.; Spella, M.; Taraviras, S.; Lygerou, Z. Reduced Geminin levels promote cellular senescence. Mech Ageing Dev 2013, 134, 10-23, doi:10.1016/j.mad.2012.10.001.

181. Pellegata, N.S.; Antoniono, R.J.; Redpath, J.L.; Stanbridge, E.J. DNA damage and p53-mediated cell cycle arrest: a reevaluation. Proc Natl Acad Sci U S A 1996, 93, 15209-15214, doi:10.1073/pnas.93.26.15209.

182. Ozaki, T.; Nakagawara, A. Role of p53 in Cell Death and Human Cancers. Cancers (Basel) 2011, 3, 994-1013, doi:10.3390/cancers3010994.

183. Chen, J. The Cell-Cycle Arrest and Apoptotic Functions of p53 in Tumor Initiation and Progression. Cold Spring Harb Perspect Med 2016, 6, a026104, doi:10.1101/cshperspect.a026104. 